\title{
Combined fluvial and pluvial urban flood hazard analysis: concept development and application to Can Tho city, Mekong Delta, Vietnam
}

\author{
Heiko Apel ${ }^{1}$, Oriol Martínez Trepat ${ }^{1}$, Nguyen Nghia Hung ${ }^{2}$, Do Thi Chinh ${ }^{1,2}$, Bruno Merz $^{1}$, and Nguyen Viet Dung ${ }^{1,2}$ \\ ${ }^{1}$ GFZ German Research Centre for Geosciences, Potsdam, Germany \\ ${ }^{2}$ Southern Institute of Water Resources Research SIWRR, Ho Chi Minh City, Vietnam
}

Correspondence to: Heiko Apel (heiko.apel@gfz-potsdam.de)

Received: 12 June 2015 - Published in Nat. Hazards Earth Syst. Sci. Discuss.: 26 August 2015

Revised: 29 February 2016 - Accepted: 21 March 2016 - Published: 13 April 2016

\begin{abstract}
Many urban areas experience both fluvial and pluvial floods, because locations next to rivers are preferred settlement areas and the predominantly sealed urban surface prevents infiltration and facilitates surface inundation. The latter problem is enhanced in cities with insufficient or non-existent sewer systems. While there are a number of approaches to analyse either a fluvial or pluvial flood hazard, studies of a combined fluvial and pluvial flood hazard are hardly available. Thus this study aims to analyse a fluvial and a pluvial flood hazard individually, but also to develop a method for the analysis of a combined pluvial and fluvial flood hazard. This combined fluvial-pluvial flood hazard analysis is performed taking Can Tho city, the largest city in the Vietnamese part of the Mekong Delta, as an example. In this tropical environment the annual monsoon triggered floods of the Mekong River, which can coincide with heavy local convective precipitation events, causing both fluvial and pluvial flooding at the same time. The fluvial flood hazard was estimated with a copula-based bivariate extreme value statistic for the gauge Kratie at the upper boundary of the Mekong Delta and a large-scale hydrodynamic model of the Mekong Delta. This provided the boundaries for 2-dimensional hydrodynamic inundation simulation for Can Tho city. The pluvial hazard was estimated by a peak-over-threshold frequency estimation based on local rain gauge data and a stochastic rainstorm generator. Inundation for all flood scenarios was simulated by a 2-dimensional hydrodynamic model implemented on a Graphics Processing Unit (GPU) for time-efficient flood propagation modelling. The combined fluvial-pluvial flood scenarios were derived
\end{abstract}

by adding rainstorms to the fluvial flood events during the highest fluvial water levels. The probabilities of occurrence of the combined events were determined assuming independence of the two flood types and taking the seasonality and probability of coincidence into account. All hazards - fluvial, pluvial and combined - were accompanied by an uncertainty estimation taking into account the natural variability of the flood events. This resulted in probabilistic flood hazard maps showing the maximum inundation depths for a selected set of probabilities of occurrence, with maps showing the expectation (median) and the uncertainty by percentile maps. The results are critically discussed and their usage in flood risk management are outlined.

\section{Introduction}

Floods are among the most damaging natural disasters, as statistics of the insurance industry regularly show $(\mathrm{Mu}-$ nichRe, 2015). A large share of the damages caused by floods occurs in urban areas, where most of the assets and population are concentrated. Rapid urban development increases the exposure to floods on the one hand, while climate change including sea level rise increases the hazard, especially in coastal and estuarine regions (Merz et al., 2010). Assessing flood hazards and risks, preparing effective flood mitigation measures, and utilizing flood benefits at the same time have thus become an even more vital task in water resource planning and flood management. 
In urban areas different flood pathways typically exist. Because locations next to rivers are preferred settlement locations and because the predominantly sealed urban surface prevents infiltration into the ground, both fluvial and pluvial floods typically occur in urban areas. This situation is exacerbated in coastal cities or cities in river deltas, where the low topographical gradient limits the drainage capacity and tidal influences and storm surges can cause additional fluvial inundation. Thus floods of different origins are a main hazard for the world's river deltas (Renaud et al., 2013; Syvitski and Higgins, 2012; Syvitski, 2008). Particularly prone to this combination of flood types are Asian megacities with their extraordinary urban growth, their location at major rivers under a pronounced monsoonal flood regime, and heavy precipitation caused by cyclones (Chan et al., 2012). Another important aspect, particularly in Asia, is the low coordination of water resources and flood management of riparian countries in a river basin, where changes in flood hazards can be caused by upstream water management measures, as shown for the Mekong by Kuenzer et al. (2013a).

Despite the large impact of urban inundation by different pathways, flood hazard and risk assessments are typically restricted to a single flood type. A growing number of fluvial flood hazard analyses can be found in literature, particularly in the last decade with growing computational capabilities and a particular shift towards probabilistic hazard and risk assessments. Examples for thematic and methodological advances in fluvial hazard or risk assessments are Apel et al. (2004, 2008), Merz and Thieken (2005), Hall et al. (2005), McMillan and Brasington (2008), Vorogushyn et al. (2010), Arrighi et al. (2013), de Bruijn et al. (2014), and Falter et al. (2015).

Pluvial flood hazard analyses are less frequently found in the literature. This can be explained by the inherent complexity of defining and quantifying these events and by the large spatial heterogeneity of the inundation causing rainfall events. Note that this statement refers to hazard analyses, i.e. quantitatively defining rainfall events and their flood impact in a spatially explicit manner including an estimation of the probability of occurrence of the rainfall events. Traditionally, the probability of rainfall events is quantified by intensity-duration-frequency (IDF) curves, which are often established for meteorologically similar regions. However, stochastic, spatially explicit rainfall simulators are also used in order to fully describe possible rainfall intensities and their spatial coverage (Burton et al., 2008; Hundecha et al., 2009; Willems, 2001; Wheater et al., 2005). Studies using synthetic rainfall events associated with probabilities of occurrence for flood inundation modelling for the derivation of pluvial flood hazard maps are, however, not very frequent. Examples of full pluvial flood hazard analyses are Nuswantoro et al. (2014) or Blanc et al. (2012).

Studies considering the combined effects of fluvial and pluvial flooding are very rare. In fact only three studies were found. Chen et al. (2010) performed a scenario-based inunda- tion modelling study considering the combination of fluvial and pluvial floods for a small city area in the UK. A fluvial flood with a return period of 200 years was with a dyke overtopping scenario and a synthetic dyke breach scenario. These two fluvial scenarios were combined with rainfall scenarios of different probabilities of occurrence. The rainfall intensity was assumed to be uniform over the simulation area. However, due to the limited number of fluvial scenarios and the absence of an estimation of the joint occurrence of the fluvial and pluvial events, the study is not a hazard analysis, but rather a sensitivity and feasibility study, as the authors acknowledge. Another study in this direction was published by Thompson and Frazier (2014), who analysed the joint occurrence of hurricane-induced coastal flooding with heavy precipitation. But in this study the probabilities of occurrence of coastal and pluvial floods were also not fully defined, as well as the probability of their joint occurrence. Just recently Breinl et al. (2015) published a study where a framework for estimating the probabilities of joint occurrence of fluvial and pluvial floods was developed. In their study the authors focus on a catchment-scale analysis, including a multi-site weather generator and a hydrological model to estimate the joint occurrence of pluvial and fluvial flood days in the city of Salzburg. The framework explicitly accounts for dependency of the triggering rainfall of the fluvial and pluvial floods. Using the stochastic weather generator, long time series of peak discharges and precipitation within the city were generated. By this the joint occurrence of fluvial and pluvial flood days could be quantified. However, only the magnitudes in terms of peak discharge and precipitation were quantified, not the consequences. This means that no inundation modelling was included, and thus hazard maps suitable for a risk assessment were not derived. As the core element of the framework of Breinl et al. (2015) is a multi-site weather generator, it requires a solid precipitation database and considerable effort for the construction of the actual weather generator, which is likely to put some restriction on the applicability of the method for data-sparse regions or very large catchments.

Based on these observations this study aims to develop a concept for joint and spatially explicit fluvial and pluvial hazard analyses, by which the probabilities of occurrences and the magnitudes for both flood types as well as their combinations are quantified. Additionally, spatially explicit probabilistic hazard maps are derived, depicting the individual as well as the combined hazard. The study also contains an analysis of some natural uncertainty sources, in order to consider the natural variability of the flood triggering events.

The study was developed in a tropical setting, and takes Can Tho city in the Mekong Delta as an example. Can Tho experiences both fluvial and pluvial floods, which occur during the monsoon season. Thus both flood types may coincide, although they are independent from each other in the given meteo-hydrological setting. A core motivation for taking Can Tho as an example is that a flood hazard or risk analysis has never been performed for the city. Flood mitigation planning 


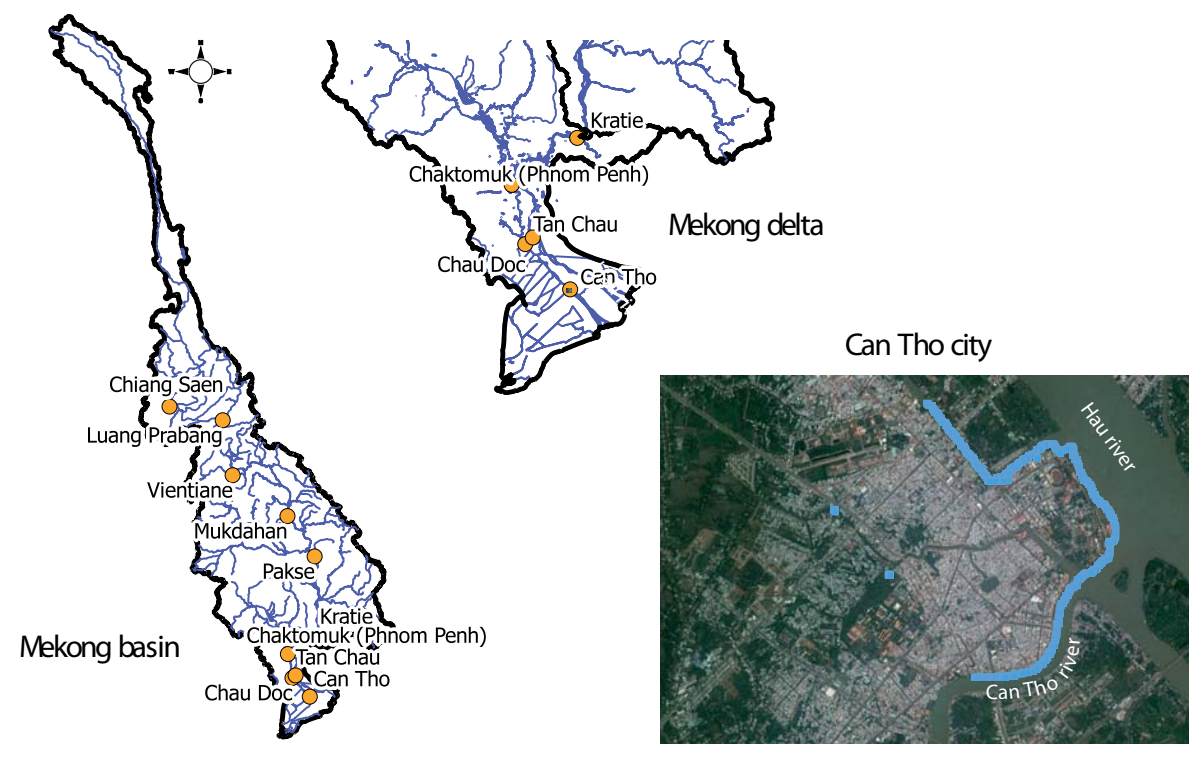

Figure 1. Sketch of the geographical setting of the study: the whole Mekong basin, the Mekong Delta with the main gauging stations, and Can Tho city. The area shaded in grey in the Can Tho city image shows the modelling domain and the blue dots indicate the fluvial boundaries of the hydraulic model.

is, if existing, based on experiences of past floods only. The presented study might therefore be used as a basis for flood mitigation planning for Can Tho city, if the discussed limitations are taken into account. Can Tho city can also be taken as a role model for growing cities in delta regions in the tropics, where fluvial floods and heavy convective rains typically occur in the same period. Therefore, the developed method might also serve as a blueprint for flood hazard analyses in the tropics.

\section{Study area and data}

\subsection{Study area}

Can Tho city is the largest city and the economic hub of the Vietnamese part of the Mekong Delta with about 1.2 million inhabitants (in 2011). It is located at the junction of the Hau River (Bassac) and the Can Tho River in the Vietnamese part of the Mekong Delta (Fig. 1). The centre of the city is the heart of the Ninh Kieu district, located directly north of the junction, bordering both Hau and Can Tho Rivers. The study is restricted to this part of Ninh Kieu, because a digital elevation model (DEM) of sufficient resolution was available for this part of the city only. No large-scale flood defences exist in Ninh Kieu. However, within the Vietnam Urban Upgrading Project - Can Tho city sub-component (2004-2014) and Mekong Delta Region Urban Upgrading Project - Can Tho city sub-component (2012-2017) road curbs and house entrances were and are elevated in order to reduce inundation of urban areas surrounding major roads. The distance to the coast is about $80 \mathrm{~km}$, but due to the low topography and river gradient the tidal signal is still strong in Can Tho, even during high flood stages. Flood events are thus typically a combination of high water levels during the annual floods and a high tide. This results in water levels exceeding the river banks for the time of the semi-diurnal high tides, causing inundations of short duration in the vicinity of the river banks. High water levels in Can Tho causing inundation typically occur late in the flood season from September to November.

Next to the two large rivers a number of channels can be found in and around the city. Inundation can also occur by bank overtopping of these channels. The water levels in these channels at the model domain boundary differ from the main rivers and need to be considered explicitly in a fluvial hazard analysis. However, gauge data for these channels do not exist and cannot be derived from the gauge in Can Tho. Thus the whole hydraulic system surrounding Can Tho, i.e. the whole Mekong Delta, has to be considered in order to derive consistent boundary conditions for the hydraulic model. The topography of the city is very low ranging, between $1 \mathrm{~m}$ and $2.5 \mathrm{~m}$ a.s.l. (Fig. 2). Most parts of Ninh Kieu are urban areas with built-up houses and infrastructure. Housing typically extends to the very river banks and in some cases even exceeds them, with houses partially on stilts in the rivers or channels.

\subsection{Data}

For Ninh Kieu a DEM with a $15 \mathrm{~m}$ resolution derived from topographical maps exists and has been used for hydraulic modelling by Huong and Pathirana (2013).The same DEM was used in this study (Fig. 2, top panel). The simulation do- 


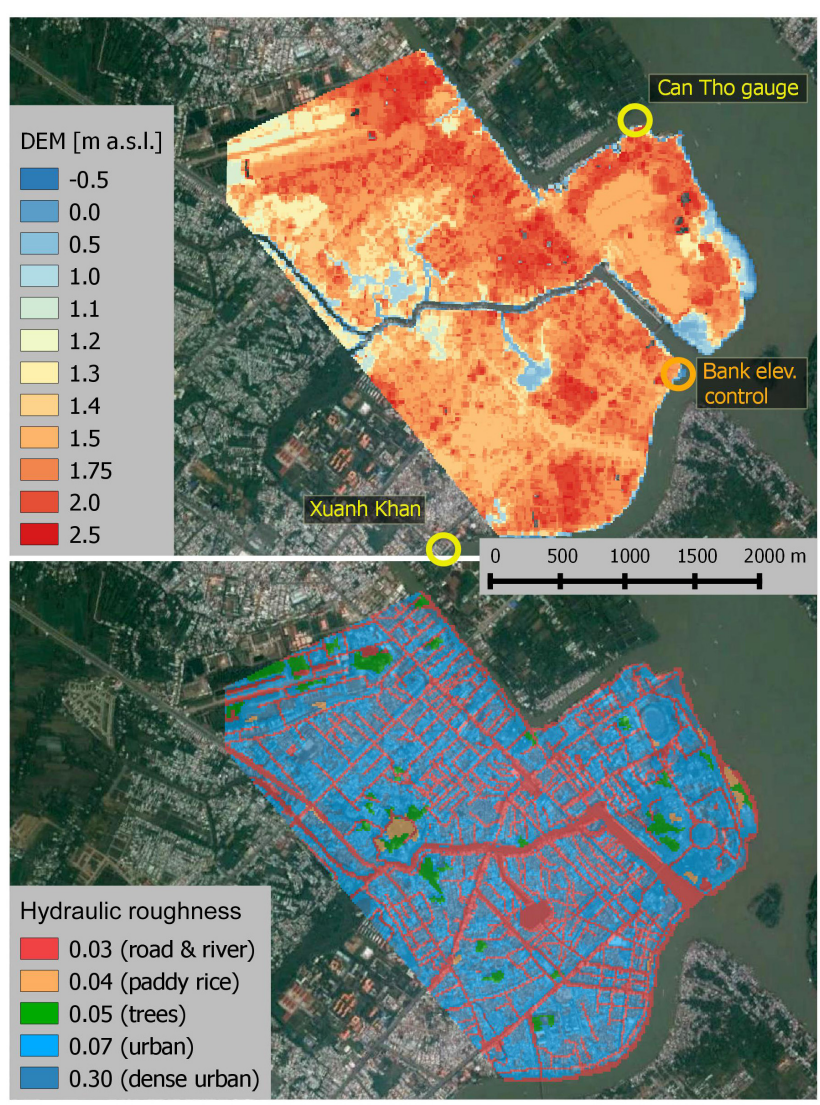

Figure 2. Top panel: central part of Can Tho city with DEM overlay. The yellow circles indicate gauge locations, the orange circle the location of the river bank, where Takagi et al. (2015) measured water levels which were used for correcting the datum of the DEM. Bottom panel: central part of Can Tho with hydraulic roughness map (Manning's $n$ values) derived from land use classification.

main consists of $243 \times 264$ grid cells. In Ninh Kieu a sewer system exists, consisting of open channels and underground pipes. However, the sewer system is reportedly not capable of draining flood waters, neither pluvial nor fluvial, due to its limited capacity. Additionally, the sewer system is not well maintained and malfunctioning in many parts (Huong and Pathirana, 2013), reducing the flood sewer capacity even further. Thus in this study the sewer system is neglected in the hydraulic flood simulations.

A land use classification based on high resolution RapidEye satellite data with $5 \mathrm{~m}$ resolution was derived by the German Aerospace Center (DLR) using the algorithms presented in Huth et al. (2012). The $5 \mathrm{~m}$ resolution data was resampled to $15 \mathrm{~m}$ to be in line with the DEM. Based on the land use classes, five roughness classes were derived (Fig. 2). For this study we adopt an urban porosity approach of assigning high roughness values to dense built-up areas. This aims at reproducing the hydraulic resistance of buildings to urban inundation flows.
Water level records were collected for the main river gauge of Can Tho in the Hau River and a gauging station was installed in the Can Tho River within the Water-related Information System for a Sustainable Development of the Mekong Delta (WISDOM) project (http://www.wisdom.eoc. dlr.de) which was datum-referenced to the main gauge. The locations of the gauges are indicated in Fig. 2 (top panel). A comparison of the recorded and modelled water levels for the flood event 2011 with the bank elevation revealed that the bank elevation as determined by the DEM was too high compared to the gauge records. Even for extraordinary high water levels as experienced during the flood event in 2011 the banks as given in the DEM were not overtopped and thus no inundation would occur (Fig. 3, top panel). This indicates a datum error or at least a discrepancy between gauge data and DEM. Thus the DEM datum had to be corrected. This was performed by comparing the water levels recorded for the flood event in 2011 with the elevation of a river bank stretch along the Hau River (orange circle in Fig. 2, top panel) and information about inundation depths from household surveys near the river (Chinh et al., 2016). This comparison suggested that the DEM datum should be corrected by $-0.5 \mathrm{~m}$ in order to provide inundation depths comparable to the surveyed depths. This correction war corroborated by surveyed water levels of Takagi et al. (2015). They surveyed water levels relative to the river bank at the same point as above in March 2012. Following their records the bank elevation of the DEM had to be reduced by $0.5 \mathrm{~m}$ as well in order to produce a similar picture as in Takagi et al. (2015) compared to the gauge records (Fig. 3, bottom panel). Thus we corrected the datum of the DEM by $-0.5 \mathrm{~m}$.

For the pluvial flood hazard analysis, hourly rainfall records from the rainfall gauge at Can Tho airport were obtained. These span a time series of 30 years from 1982 to 2012. Figure 4 shows the time series along with the annual maxima. The highest recorded hourly rainfall in this period was $87 \mathrm{~mm} \mathrm{~h}^{-1}$. The figure shows that the rainfall is distinctively seasonal with high rainfall amounts during the monsoon season (May-October) and little rainfall during the remaining time of the year. Next to the annual maximum a large number of additional high rainfall events are obvious in the data series. This calls for a peak-over-threshold (POT) approach for the frequency analysis of heavy rainfall events, which will be explained further in Sect. 3.2.

\section{Methods}

\subsection{Fluvial hazard analysis}

The fluvial hazard analysis comprises two basic components:

1. a 2-D hydraulic model for the simulation of the flood propagation in the study area 

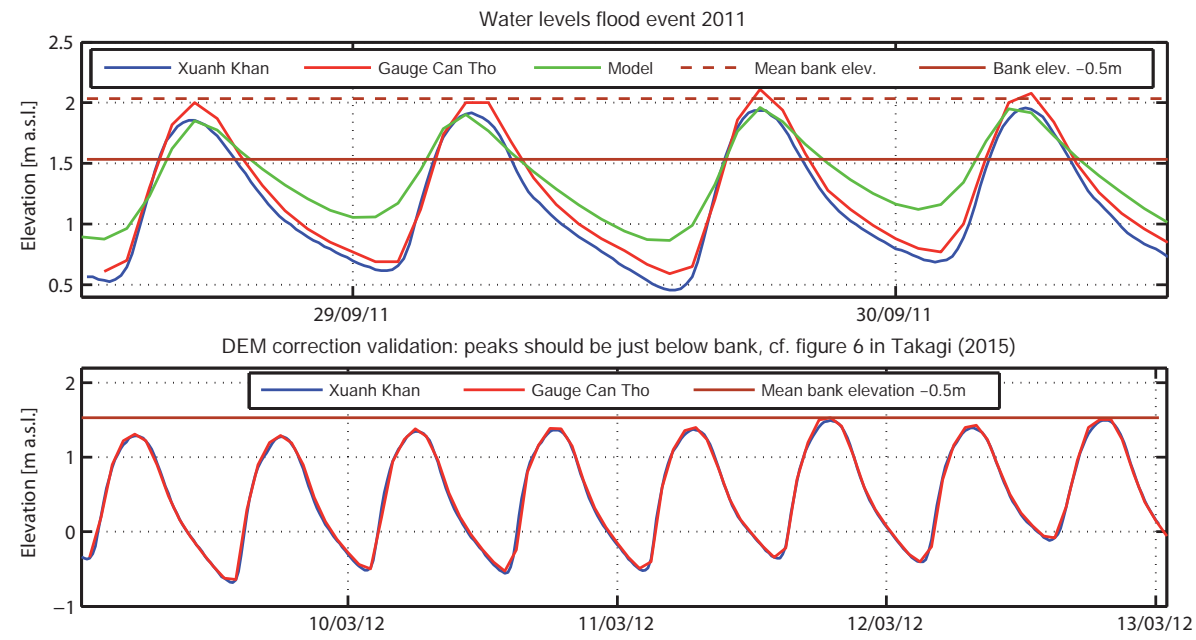

Figure 3. Correction of datum error of DEM. Top panel: comparison of bank elevation Ninh Kieu extracted from DEM and monitored and modelled water levels for the flood event 2011. Bottom panel: comparison of bank elevation extracted from corrected DEM with measured water levels and field campaign data published in Takagi et al. (2015).

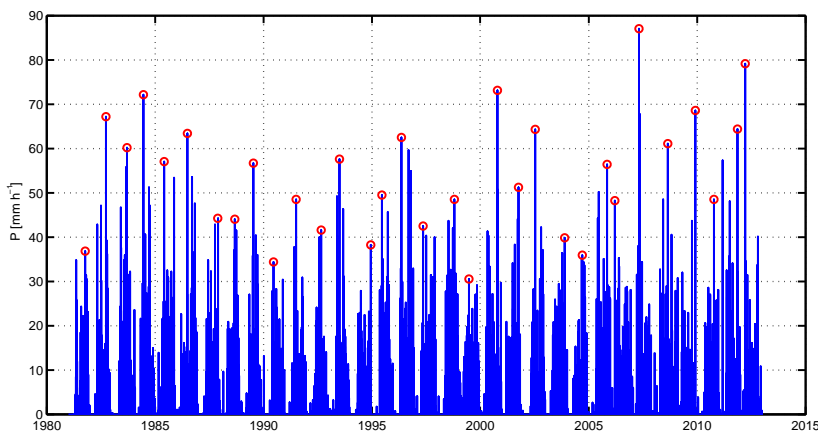

Figure 4. Hourly rainfall Can Tho gauge 1982-2012 with annual maxima marked by red circles.

2. an extreme value statistic for the estimation of the probability of occurrence of flood events of certain magnitudes.

These two components are described in detail in the following sections.

\subsubsection{Hydraulic model}

The hydraulic model for Ninh Kieu was developed on the basis of the 2-dimensional formulation of the shallow water equations solving the momentum (Eq. 1) and continuity (Eq. 2) equations numerically on a grid as described in Bates et al. (2010):

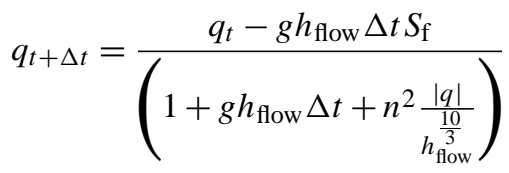

$\frac{\partial h^{i, j}}{\partial t}=\frac{q_{x}^{i-1, j}-q_{x}^{i, j}+q_{y}^{i-1, j}-q_{y}^{i, j}}{\Delta x y}$,

where $t$ is time; $\Delta t$ is the time step; $q$ is the specific flow per unit width; $i, j$ are cell indices; $h_{\text {flow }}$ is the flow depth between cells, i.e. the difference between the maximum water elevation (surface elevation + water depth) and the maximum surface elevation between two adjacent cells; $g$ is the acceleration of gravity; $n$ is Manning's roughness coefficient; $S_{\mathrm{f}}$ is the friction slope; $h$ is the water depth, and $\Delta x y$ is the size of the square cells. The flow is represented by $q_{x}$ in $x$ direction(horizontal in grid space) and $q_{y}$ in $y$ direction (vertical in grid space). Cell index $i$ enumerates the cells in $x$ direction, $j$ in $y$ direction. The continuity Eq. (2) for each grid cell $i, j$ is thus a mass balance of flows in and out of the cell in both $x$ and $y$ direction.

The internal model time step is determined analogously to the Courant-Friedrichs-Lewy criterion:

$\Delta t_{\max }=\alpha \frac{\Delta x y}{\sqrt{g h_{\text {flow }}}}$,

where $\alpha$ denotes an empirical coefficient reducing the time step determined by the Courant-Friedrichs-Lewy criterion to ensure model stability and is set to 0.8 .

The implemented model is grid-based and thus able to simulate flood propagation directly on the basis of the provided DEM. Rivers and channels are also modelled in 2-D in contrast to the LISFLOOD-FP implementation of Bates et al. (2010). Flows are calculated between cells, based on the water depths and surface elevations of the neighbouring cells. Thus routing precipitation causing overland flow is quite simple and straightforward: at each time step the spatially distributed precipitation (given in $\mathrm{mm}$ depth) is added to the inundation depths of the affected grid cells. By this the 
inundation depths of the grid cells are updated each time step and consequently the hydraulic gradients change, resulting in flow. This simple and effective way of routing rainfall is another benefit of grid-based inundation models, particularly for the present study.

Hydraulic models based on simplified shallow water equations have been proven to be an adequate choice for the simulation of flood propagation and inundation in many flood hazard studies, for example Apel et al. (2009), de Almeida and Bates (2013), Dimitriadis et al. (2016), Fewtrell et al. (2011). For the typical shallow inundation depths in fluvial and pluvial floods (except flash floods) with subcritical flow conditions, the simplified models yield comparable results to models based on the full shallow water equations, but with significantly lower computation cost. Thus the use of such a model in the presented study is well justified, particularly considering the slow inundation propagation and low surface gradients.

In order to speed up simulation runtime, the model code was implemented on a Graphics Processing Unit (NVIDIA Tesla C1060 GPU) using Portland CUDA Fortran. The NVIDIA Tesla C1060 GPU card contains 240 processor cores enabling a highly parallelized execution of the model code in the spatial domain. The parallelization of the model is handled internally and automatically on a single GPU card and does not require user intervention for domain decomposition and synchronization. This makes the use of GPU for general purpose computing highly attractive. However, code adaptation and reimplementation in CUDA Fortran requires investing time and effort.

Hydraulic models need to be calibrated, mainly by adjusting the hydraulic roughness. This was attempted by simulating the large inundation events from 2011. Two large fluvial events occurred between 26 September and 2 October, and between 24 and 31 October 2011, with peak water levels at 29 September and 29 October. In the aftermath of the events a household survey was conducted in which the inundation depth was estimated by the house owners (Chinh et al., 2016). Additionally, maps showing the inundation extent based on TerraSAR-X Stripmap satellite images with $2.75 \mathrm{~m}$ spatial resolution covering particular days in the flood season were provided by the German Aerospace Center (DLR). Unfortunately the satellite maps do not cover the peak water levels exactly. For the September event, an image one day after the peak water level was available, while for the event in October no image was taken during the entire event. A closer inspection of the mapped inundation extent for 30 September revealed that only a few inundated areas are classified within the city limits, in contrast to the actual observed flood. The detected inundation areas are concentrated on the main roads and wider channels. This behaviour is caused by reflection artefacts of the radar signals from building walls and the close distance of the buildings in streets causing overradiation of pixels and thus erroneous classification. These intrinsic errors of radar images used for flood mapping in ur-

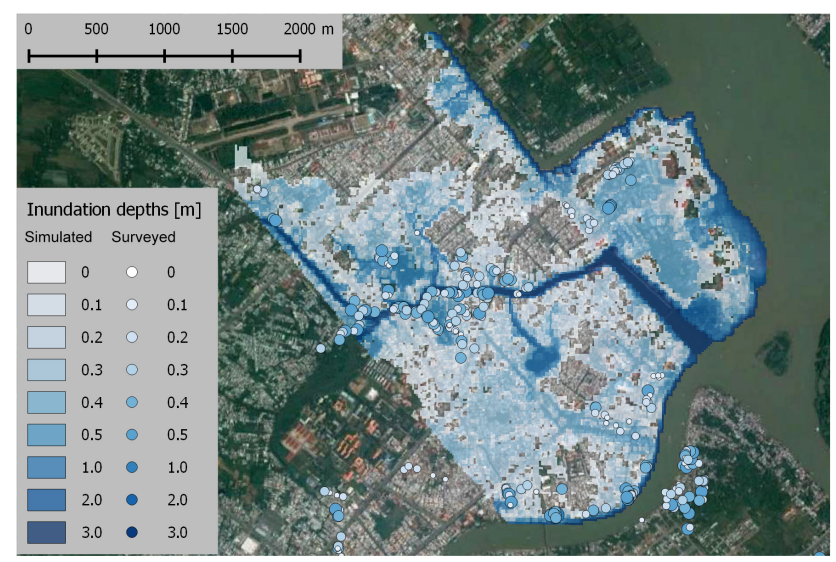

Figure 5. Plausibility check of the hydraulic model: maximum inundation depth of the simulated flood event 2011 and surveyed water depth inside inundated houses (dots).

ban areas are reported by Kuenzer et al. (2013b), taking Can Tho city and province as an example. Due to the temporal mismatch and the underestimation of the inundation extent in densely settled areas, the satellite-based flood-extent maps could not be used for the calibration/validation of the hydraulic model, unlike in previous large-scale hydrodynamic modelling studies in the Mekong Delta (Dung et al., 2011; Manh et al., 2014).

In the household interviews the owners provided information of the inundation depths inside their houses, i.e. water depth relative to the ground floor level. However as the ground floor levels vary greatly in relation to the street level, depending on construction details and precautionary measures of the owners, the recorded inundation depths in the house cannot be compared to simulated inundation depths based on the DEM at hand. It was only possible to check the model simulations for plausibility using the information from the survey as indicators for being inundated or not, i.e. as a rough and incomplete estimate for the inundation extent. Figure 5 shows the result of the simulation of the 2011 flood in terms of maximum inundation depths and the reported inhouse water depths. The colour coding of the simulation and survey data can serve as an indication of a plausible model performance in terms of inundation depths, but given the conceptual mismatch between the simulated inundation depths and the surveyed water depths inside the houses, this is just an indication. However, it can definitively be stated that at every location of inundated houses the model also simulated an inundation, which is the most robust statement regarding model performance that can be made. But as by far not all flooded households were surveyed, the model performance in terms of overall inundation extent cannot be assessed conclusively with the present data. The described plausibility check does not provide any quantitative measure of model performance, but rather a positive qualitative feedback about the applicability of the model for the given purpose. Given the 
quality of the DEM and validation data at hand, the performance of the 2-D hydraulic model was assessed as plausible and suitable for the purpose of the study.

\subsubsection{Boundary conditions of the hydraulic model}

In order to simulate meaningful flood propagation, boundary conditions have to be provided for the simulation domain along the Hau and Can Tho Rivers as well as for the channels entering the simulation domain on the western border. These boundary conditions have to be associated with probabilities of occurrence in order to obtain a hazard analysis. As gauge data sufficient for an extreme value statistic were not available, particularly for the channels, the boundary conditions for the Can Tho model were derived from a large-scale hydraulic model for the whole Mekong Delta (Dung et al., 2011). The boundary conditions for the Mekong Delta model were derived for the gauge Kratie in Cambodia denoting the upper boundary of the Mekong Delta. A copula-based bivariate extreme value statistic is performed, using annual maximum discharge $Q_{\max }$ and flood volume $V$ and standardized hydrographs, which are scaled to the maximum discharge and flood volume for given annual probabilities of non-exceedance. The method is extensively described in Dung et al. (2015), thus it is not repeated here. From the different statistical models tested in Dung et al. (2015), the Gumbel-Hougaard copula with the marginals of $Q_{\max }$ and $V$ described by log-normal distributions is used. Synthetic scenarios were derived for annual probabilities of nonexceedance of $p=0.5,0.8,0.9,0.95,0.98,0.99$, whereas for each probability level, 140 combinations of annual maximum discharge $Q_{\max }$ and flood volume $\mathrm{V}$ were drawn in a MonteCarlo process from the curves shown in Fig. 6 in Dung et al. (2015). This resulted in $6 \times 140=840$ flood scenarios altogether, which were simulated by the large-scale hydraulic model.

From these scenarios the simulated water levels along the Hau River, Can Tho River and the channel were taken as boundary conditions for the 2-D hydraulic model of the study area. To save computational time, the 2-D simulation period was set to six days around the maximum water level of each flood scenario at the Hau River. This period is equivalent to the length of the spring tides in the Mekong Delta (Wassmann et al., 2004). This limitation can also be justified from a technical point of view, because sensitivity runs showed that the maximum inundation depth and extent do not change with longer simulation periods. This is due to the distinct tidal influence on the water levels, which exceed the bank levels during maximum water levels, typically during spring tides and for short periods only. During low tides the water can drain back into the river. Figure 7 shows the Monte Carlo derived boundary conditions for all probability levels for both river and channel.

The inundation simulations resulting from these boundary conditions resulted in 140 inundation maps for Can Tho

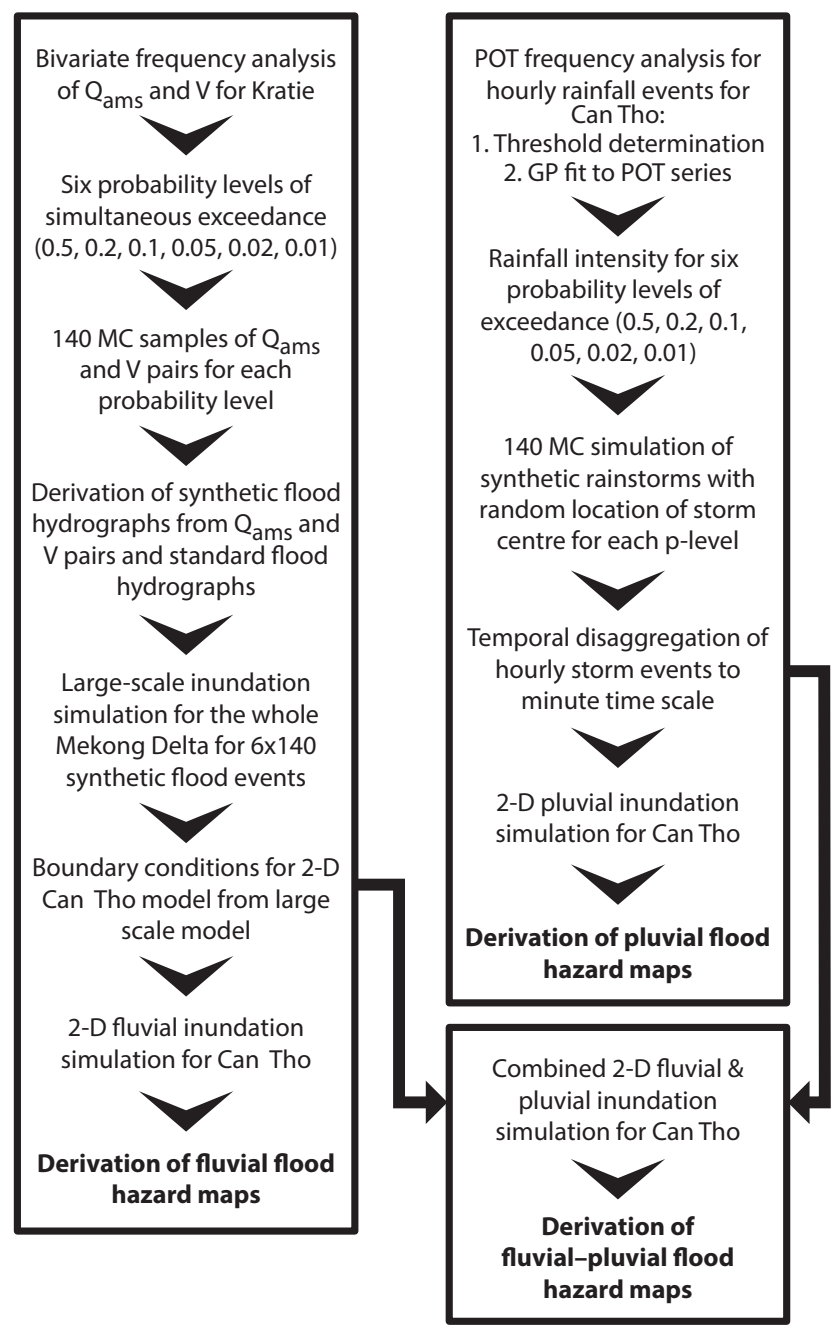

Figure 6. Scheme of the fluvial, pluvial and combined hazard analysis.

showing maximum inundation depths for every six probability levels. For each probability level, the maximum inundation maps were evaluated per grid cell, calculating the median maximum inundation depth and the 5 and $95 \%$ quantiles, as performed by Vorogushyn et al. (2010). These probabilistic hazard maps are the final product of the proposed fluvial hazard analysis. The median hazard maps serve as the expectation (in a statistical sense) for the flood hazard of a given probability of occurrence, while the 5 and $95 \%$ percentile maps quantify the uncertainty, stemming from the natural variability of the inundation processes (natural or aleatory uncertainty; Merz and Thieken, 2005). Figure 6 summarizes the different steps of the fluvial flood hazard analysis in a flow chart. 

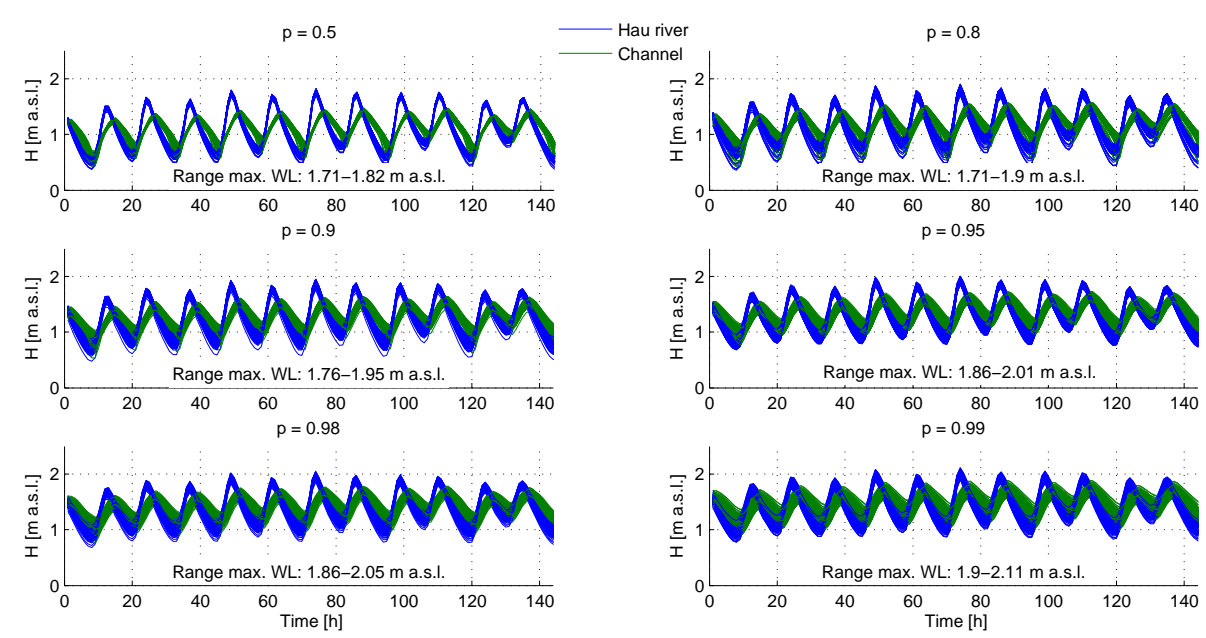

Figure 7. Boundary conditions for the fluvial hazard analysis: Hau and Can Tho Rivers (blue) and the channels entering the modelling domain from theWest (green). $p$ denotes the annual probabilities of non-exceedance. Simulation time is six days around the maximum water level in the Hau River. For each $p$ level 140 simulations were performed. The spread of the boundary time series denotes the variability stemming from the bivariate extreme value statistic, which increases with higher annual probabilities of non-exceedance.

\subsection{Pluvial hazard analysis}

The pluvial hazard analysis comprises three components: a statistical analysis of extreme rainfall events in Can Tho, the derivation of spatially distributed synthetic rainstorms, and a 2-D hydraulic model. The hydraulic model for the pluvial hazard analysis is the same as described in Sect. 3.1.1, but with different boundary conditions. In order to exclude fluvial inundation the river boundaries were set to low water levels never exceeding the river banks and allowing for outflow from the simulation domain. The boundaries of the model domain were set by adding spatially distributed rainfall volumes derived from the statistical analysis and synthetic rainstorms to each grid cell with a time step of $60 \mathrm{~s}$. The statistical analysis and derivation of synthetic rainstorms are summarized in Fig. 6 and described in detail in the following sections.

\subsubsection{Rainfall extreme value statistics}

The basis for this analysis is the 30-year time series of hourly rainfall recorded at Can Tho airport shown in Fig. 4. The presence of many strong rainfall events besides the annual maxima calls for a peak-over-threshold (POT) analysis. POT enables a full exploitation of the information content of the time series including all hazardous storm events of the monsoon season, and thus a realistic estimation of rainfall probabilities. An inspection of the rainfall time series illustrates the very nature of the rainfall events in the region, which are convective tropical rainstorms. Almost all heavy rainfall events have a duration of $\leq 2 \mathrm{~h}$, with the majority of events lasting $\leq 1 \mathrm{~h}$. This suggests that the storm duration for this analysis can be realistically fixed to maximum $1 \mathrm{~h}$. In further analysis we even consider outbursts of shorter duration by non-uniform rainfall intensities within the maximum duration of $1 \mathrm{~h}$ (cf. Sect. 3.2.2). This is also in concordance with local experiences. The construction of IDF curves is thus not required; a POT analysis of hourly rainfall is sufficient to describe the rainfall regime.

In order to exploit the full information content of the data series, it is assumed that the events lasting two hours in the time series are in fact one hour events extending over the change of the hour. Thus the sums of two hour events are assumed as an event lasting one hour and are used for the POT analysis. It is assumed that two rainfall events are independent if the temporal distance between them is at least $24 \mathrm{~h}$. In order to determine the optimal threshold for the POT analysis several tests were conducted: a stability plot of the generalized Pareto distribution (GPD), which is used for the POT analysis, a Pareto quantile plot, a mean residual life plot and a Kolmogorov-Smirnov test. In addition, the stability of selected quantiles of the GP was tested depending on different thresholds. The results of the tests are shown in Fig. 8. All the tests indicate that a threshold of 18 or $19 \mathrm{~mm} \mathrm{~h}^{-1}$ is an appropriate choice. Thus the threshold was fixed at $18 \mathrm{~mm} \mathrm{~h}^{-1}$. Figure 9 shows the resulting maximum likelihood fit of the GP to the POT series with a threshold of $18 \mathrm{~mm} \mathrm{~h}^{-1}$ along with the empirical distribution, Gringorten plotting positions of the POT series, and a fit of a GEV distribution to the annual maxima series for comparison. The POT quantiles are much higher compared to the annual maximum analysis depicting the likelihood of several extreme rainfall events per year (in the mean 12 rainfall events per year exceeding the threshold of $18 \mathrm{~mm} \mathrm{~h}^{-1}$ ). The fitted GP is the basis for the derivation of synthetic storm events and their associated probabilities. 

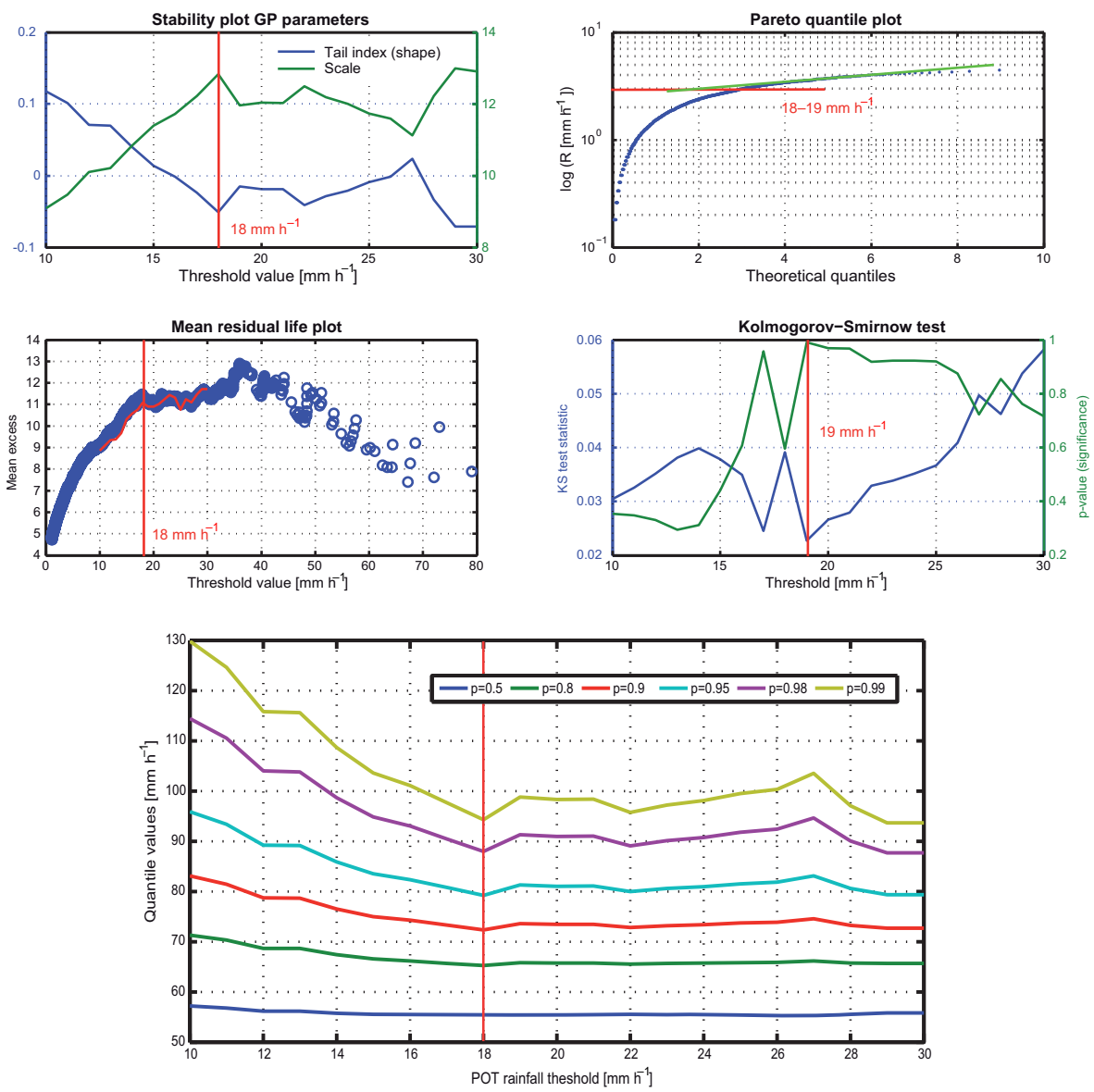

Figure 8. Threshold determination for the POT rainfall frequency analysis. Upper panel: analytical tests. For the Kolmogorov-Smirnov test the lowest KS statistic and the highest significance indicates the threshold. For the other tests the threshold is approximated by the point where trajectories deviate from an approximate linear behaviour. The red lines indicate the threshold determined by the individual tests. Lower panel: empirical test. Quantiles ( $p=$ annual probability of non-exceedance) estimated with a maximum likelihood fitted generalized Pareto distribution and different POT thresholds. The red line indicates the threshold above which the estimated quantiles are approximately stable.

\subsubsection{Synthetic storm events}

In order to simulate inundation caused by heavy rainfalls the statistically derived rainfall intensities recorded at the rain gauge are translated into a spatial rainfall fields, based on the following assumptions:

1. the rainfall events do not cover the whole study area with uniform intensity

2. the extent of the convective rainfall cell is assumed to be circular

3. the intensity of the rainfall of the convective cell is highest at its centre and decreasing to the border

4. the intensity within the circular extent is distributed according to a Gaussian bell

5. the intensity along the border of the convective cell is $1 / 10$ of the maximum intensity
6. the diameter of the storm cell increases with intensity

7. the location of the storm cell is stationary during the event duration of $1 \mathrm{~h}$.

Assumption 1 is based on local observations and has been confirmed by regional meteorologists in personal communication. Assumption 2 is also confirmed by meteorologists dealing with radar rainfall observations in the region. A similar assumption was also taken by Nuswantoro et al. (2014) for a storm generator for Jakarta in Indonesia, which has similar rainfall characteristics as the South of Vietnam. Assumptions 3 to 6 are also based on observations in the area and have also been used by Nuswantoro et al. (2014) for Jakarta. Assumption 4 is reasonable for tropical rainstorm cells. This approach of describing the rainfall intensity has been adopted from the weather generator of Willems (2001). For assumption 6 the extent of the large storm events was estimated at $\approx 8 \mathrm{~km}$, based on detailed meteorological sim- 

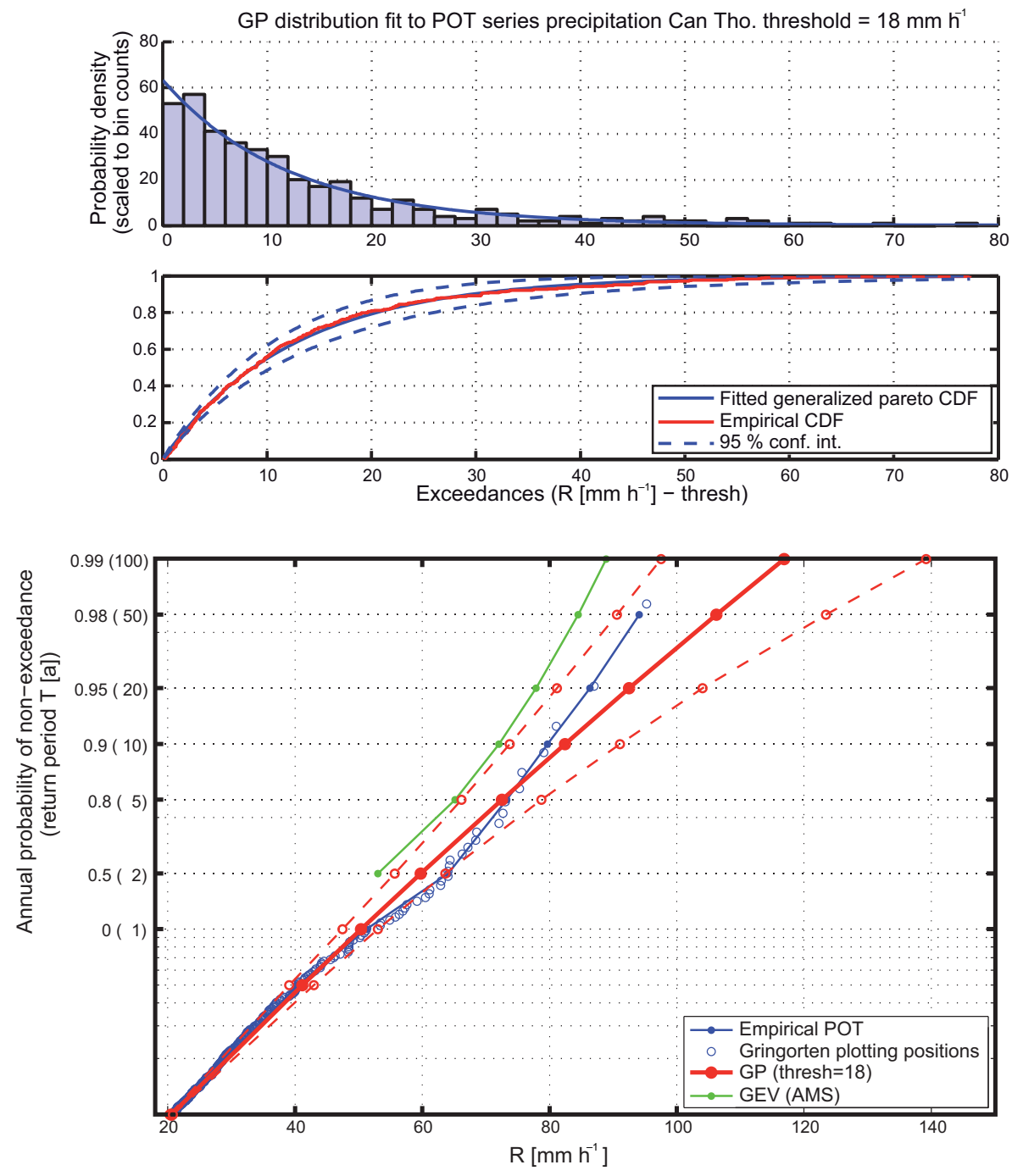

Figure 9. Fit of the GP to the hourly rainfall time series of Can Tho with POT threshold $=18 \mathrm{~mm} \mathrm{~h}^{-1}$. The lower figure shows the fitted GP distribution with $95 \%$ uncertainty bounds, the empirical POT distribution and the plotting positions for the POT series, along with a GEV distribution fitted to the annual maxima series for comparison.

ulations of two large storm events in Can Tho (both around $80 \mathrm{~mm} \mathrm{~h}^{-1}$ ) by Huong and Pathirana (2013). Table 1 lists the assumed relation of annual probability of non-exceedance $\mathrm{p}$, rainfall intensity $R(p)$, and extent of the storm cells at the full width at tenth of maximum (FWTM). The functional relation between FWTM and $R(p)$ was empirically derived as FWTM $=R(p) \cdot 90$, based on the simulated storm events in Huong and Pathirana (2013). Figure 10 shows two synthetic storm events resulting from this procedure for annual probabilities of non-exceedance of 0.5 and 0.99 .

In order to compensate for the negligence of the movement of convective storm cells (assumption 7), the pluvial hazard analysis was embedded in a Monte Carlo analysis randomizing the location of the storm centres. Through this procedure, the random nature of the location of the maximum rainfall is captured, but the effect of moving rainfall
Table 1. Annual probability of non-exceedance $\mathrm{p}$, associated rainfall intensity $R(p)$ as estimated with the fitted generalized Pareto distribution, and the assumed extent (FWTM, Full Width at Tenth of Maximum) of the synthetic rainstorm associated to the intensity.

\begin{tabular}{lcccccc}
\hline$p$ & 0.5 & 0.8 & 0.9 & 0.95 & 0.98 & 0.99 \\
\hline$R(p)\left[\mathrm{mm} \mathrm{h}^{-1}\right]$ & 59.79 & 72.54 & 82.43 & 92.55 & 106.20 & 116.90 \\
FWTM $[\mathrm{m}]$ & 5380 & 6528 & 7419 & 8329 & 9563 & 10521 \\
\hline
\end{tabular}

cells can also be mimicked. Analogously to the fluvial hazard analysis 140 Monte Carlo runs with random selection of storm centres over the simulation domain for each probability level were conducted. In order to test the stability of the Monte Carlo procedure in terms of spatial distribution of maximum rainfall intensity, the maximum rainfall of the syn- 
thetic rainstorms with random storm centres was evaluated at 25 evenly spaced grid cells over the simulation domain. For each grid cell the maximum rainfall intensity was extracted from the 140 synthetic storms for all probability levels. The reasoning behind this analysis is that a stable MC simulation would yield the rainfall intensity quantified by the extreme value statistics (cf. Sect. 3.2.1) at least once for the given probability level. As the box plots in Fig. 11 show, not all of the 25 grid cells received $100 \%$ of the potential maximum rainfall, i.e. some underestimation occurs at some grid cells. However, for all but the annual probability of nonexceedance $p$ of 0.5 , this negative bias is very small $(<1 \%)$ and thus negligible, particularly considering the uncertainties of the analysis. However, even for $p=0.5$, the median of the maximum rainfall of the grid cells is $98.4 \%$ of the rainfall given by the GP distribution, i.e. the bias is $-1.6 \%$ only, which can also be considered acceptable.

For simulating the inundation caused by the synthetic storm events, the events have to be disaggregated, i.e. the temporal resolution of one hour needs to be reduced to time steps appropriate for the hydraulic model. Instead of a simple uniform disaggregation we opted for a disaggregation with a distinct precipitation peak, which is more realistic for heavy convective rains. Thus the hourly intensity of the synthetic storm events was disaggregated into 60 time steps of $1 \mathrm{~min}$ by a normal distribution with $\mu=30 \mathrm{~min}$ and $\sigma=5 \mathrm{~min}$. This resulted in maximum rainfall intensities at $30 \mathrm{~min}$ after precipitation start and a concentration of the bulk of the precipitation in the 30 min surrounding the peak. This temporal disaggregation was applied to every pixel of the synthetic storm events. For the inundation simulation the rainfall amount of the disaggregated storm events was directly added to every pixel covered by the synthetic storms as surface water. The surface water was then routed by the 2-D hydraulic model with an overall simulation time of $3 \mathrm{~h}$ to allow for redistribution of the water after the end of the storm event. The resulting 140 maps of maximum inundation depths per probability level were then evaluated to create probabilistic flood hazard maps. This procedure is identical to the fluvial hazard analysis (cf. Sect. 3.1.2).

\subsection{Combined hazard analysis}

The essential question for a combined fluvial and pluvial hazard analysis is the question of dependency. At this point a clear distinction between dependence and coincidence is made: dependence infers a causal or functional relationship, i.e. in the given context one flood type would cause or influence the other, either in its probability of occurrence or its magnitude. Coincidence does not include any relationship as dependent. It is rather defined as the chances that the two flood types occur at the same time. Following these definitions, for this particular study it can be assumed that fluvial and pluvial flood events are completely independent from each other. Although they appear during the same season,

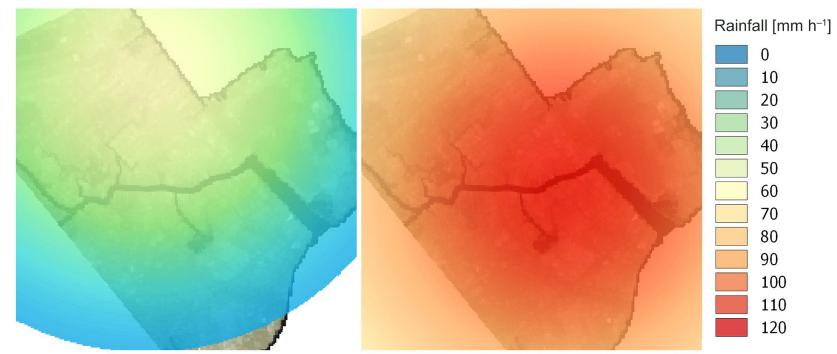

Figure 10. Examples of synthetic hourly rainfall events for annual probability of non-exceedance $p=0.5$ (left panel) and annual probability of non-exceedance $p=0.99$ (right panel). Note that the storms have different randomly drawn storm centre locations.

which is actually the prerequisite for a joint hazard analysis, the triggers for fluvial and pluvial floods in the city of Can Tho are independent. Fluvial floods are caused by the interplay of run-off generation in the Mekong basin and tidal backwater effects. On the contrary, pluvial flood events are caused by local convective rainfalls, which are strong enough to create urban inundation, but the limited spatial extent and thus rainfall volume does not cause fluvial inundation by the Hau River and channels.

The independencies of the flood triggering events have a direct consequence on the calculation of the probabilities of coinciding flood events: in a first step the joint probability of occurrence within a flood season can be quantified by the product of the individual probabilities of occurrences. For example, a joint occurrence of a fluvial flood event with an annual exceedance probability 0.5 and a pluvial flood event of probability 0.5 within the same flood season is 0.25 . However, this joint probability of occurrence within the same flood season has to be corrected by the probability that the flood events actually occur at the very same time and cause a combined flood event. This probability is termed "probability of coincidence" in the given context. Thus the probability of occurrence of joint fluvial-pluvial flood events is generally calculated as the following:

$P(\mathrm{fl} \cdot \mathrm{pl})=P(\mathrm{fl}) \cdot P(\mathrm{pl}) \cdot P(\mathrm{co})$,

with $P(\mathrm{co})$ as the probability of coincidence of fluvial and pluvial flood events.

In this study $P(\mathrm{co})$ is estimated by the typical length of the flood season in relation to the duration of the fluvial flood events. The period of the flood season in which fluvial floods in Can Tho typically appear is mid-September to the end of November, i.e. lasting about 76 days (cf. Sect. 2.1). Flood peaks of the Mekong with high water levels last typically about six days (cf. Sect. 3.1). Within these six days, 12 distinct flood peaks, i.e. periods of high water levels, occur due to the semi-diurnal tidal regime. The high water levels differ only slightly, as shown in Fig. 7. Furthermore, sensitivity runs with the hydraulic model have shown that the maximum inundation depths of a combined flood event do not 


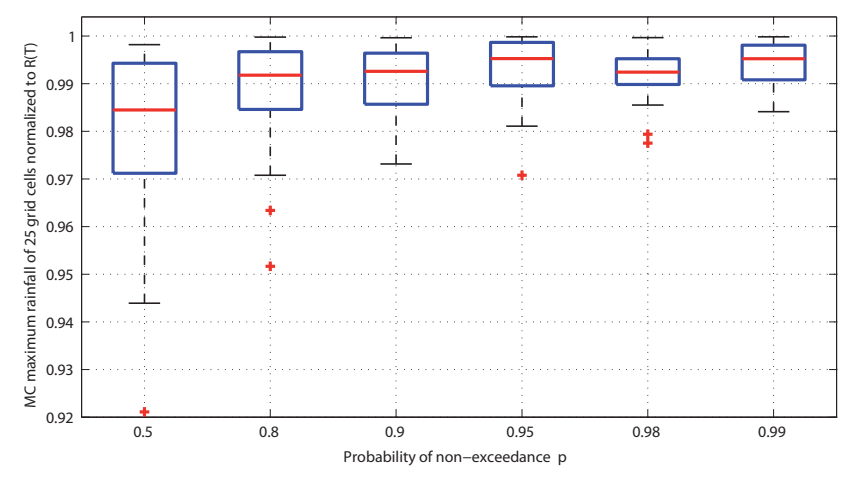

Figure 11. Estimation of the bias introduced by the assumptions taken for the synthetic rainstorm events and the random location of the storm centres in the Monte Carlo analysis. For each probability level the maximum of the 140 synthetic storm events was extracted for 25 grid cells evenly spaced over the simulation domain. The maximum rainfall was normalized to the value given by the generalized Pareto distribution fitted to the POT rainfall series. A value of 1 thus indicates zero bias. The box plots show the distribution of the maximum rainfall among the 25 grid cells.

differ significantly, if the rainstorm event occurs exact at the time of highest water level or if it occurs within $\pm 3 \mathrm{~h}$ around high water levels. This means that the sensitive time window for coincidence of a fluvial and pluvial event is 12 flood peaks $\cdot 6 \mathrm{~h}$ duration of high water levels $=3$ days within a flood period of 76 days. Considering the average number of rainfall events in the critical fluvial flood period, which amounts to $5, P(\mathrm{co})$ evaluates to five $\times 3 / 76=0.1974$. In order to account for the unavoidable uncertainty in the assumption taken for this calculation, a value of $P(\mathrm{co})=0.2$ was used for calculating the joint fluvial-pluvial flood probabilities.

For the combined fluvial-pluvial hazard analysis a set of joint flood events was simulated by combining fluvial and pluvial flood events with the same individual probability of occurrence, i.e. fluvial flood events of a probability of occurrence of 0.5 were combined with pluvial flood events of a probability of occurrence of 0.5 , fluvial events of $0.8 \mathrm{oc}-$ currence probability with pluvial events of 0.8 occurrence probability, and so forth. A complete permutation of different probability levels for fluvial and pluvial flood events was not performed in order to obtain the same number of probability levels as in the individual hazard analysis, but also to keep the required simulation time in manageable limits.

Technically, the combined fluvial and pluvial flood hazard maps were derived by simulating the 140 fluvial flood scenarios per probability level and adding a synthetic rainstorm event with a random storm centre location at the time of the maximum water level of the fluvial scenario boundary. From the 140 combined scenarios per probability level probabilistic hazard maps were derived just as for the fluvial and pluvial analysis. Figure 6 illustrates the combined hazard analysis in the overall process flow chart.

\section{Results and discussion}

\subsection{Fluvial hazard}

Figure 12 shows the probabilistic fluvial hazard maps comparing the 5,50, and $95 \%$ percentile maps for all selected probability levels. The inundation maps clearly show the inundation pathways. Inundation of the built-up area starts around the junction of the city channel and the Can Tho River, at the $90^{\circ}$ bend of the city channel in the East of the simulation domain, along the open sewer channel connected to the Can Tho River, and low lying areas around the city channel after the $90^{\circ}$ bend of the channel in the east of the simulation domain. From these locations the inundation is progressing into the urban area. A particular distinct feature is the inundation of the 30 Tháng 4 road (Road of the 30 April) crossing the sewer channel. This is in accordance with observations during inundation events.

The area most susceptible to inundation is the part of the Cái Khé ward between the Hau River and the wide part of the city channel. This area is always inundated except for the $5 \%$ quantile map of $p$ level 0.5 . This is also the area of the deepest inundation.

Figure 12 shows that the maximum inundation depths and extents have an increasing annual probability of nonexceedance, as expected. In the median quantile maps, the mean maximum inundation depth, excluding the channel and boundary cells, evaluates to $0.31 \mathrm{~m}$ for the $p$ level of 0.5 and increases to $0.36 \mathrm{~m}$ for $p$ level 0.99 (cf. Table 2). This rather slight increase in mean inundation depth is accompanied by a substantial increase in the inundated area from $2.37 \mathrm{~km}^{2}$ $(p=0.5)$ to $5.29 \mathrm{~km}^{2}(p=0.99)$. In the $50 \%$ quantile maps almost all the city area is inundated for $p$ level 0.99 .

A further noteworthy feature of Fig. 12 is the difference between the quantile maps. There are considerable differences in inundation extent, and for the higher $p$ levels also in inundation depth. This uncertainty is caused by the different pairs of maximum discharge and volume of the synthetic flood events, stemming from the extreme value analysis of the fluvial boundary described in Sect. 3.1.2. In the particular context of Can Tho city with prevailing short term flood events, the maximum discharge of the synthetic events and thus the maximum water levels play a dominant role. The maximum water level controls the overbank water level and inundation duration, because with higher maximum water levels the period of overbank water levels during a tidal cycle of six hours is also longer. Contrary to the maximum water level, the overall volume of the whole flood season does not have any impact on the local inundation in Can Tho city. Thus the range of the maximum flood discharges determined by the 140 random MC derived boundaries per $p$ level causes 


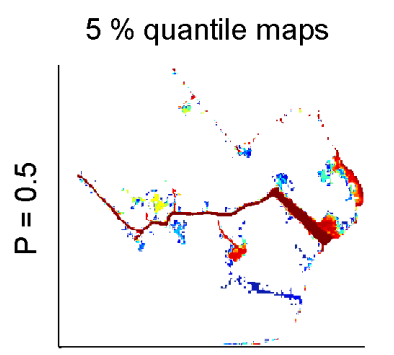

$50 \%$ quantile maps
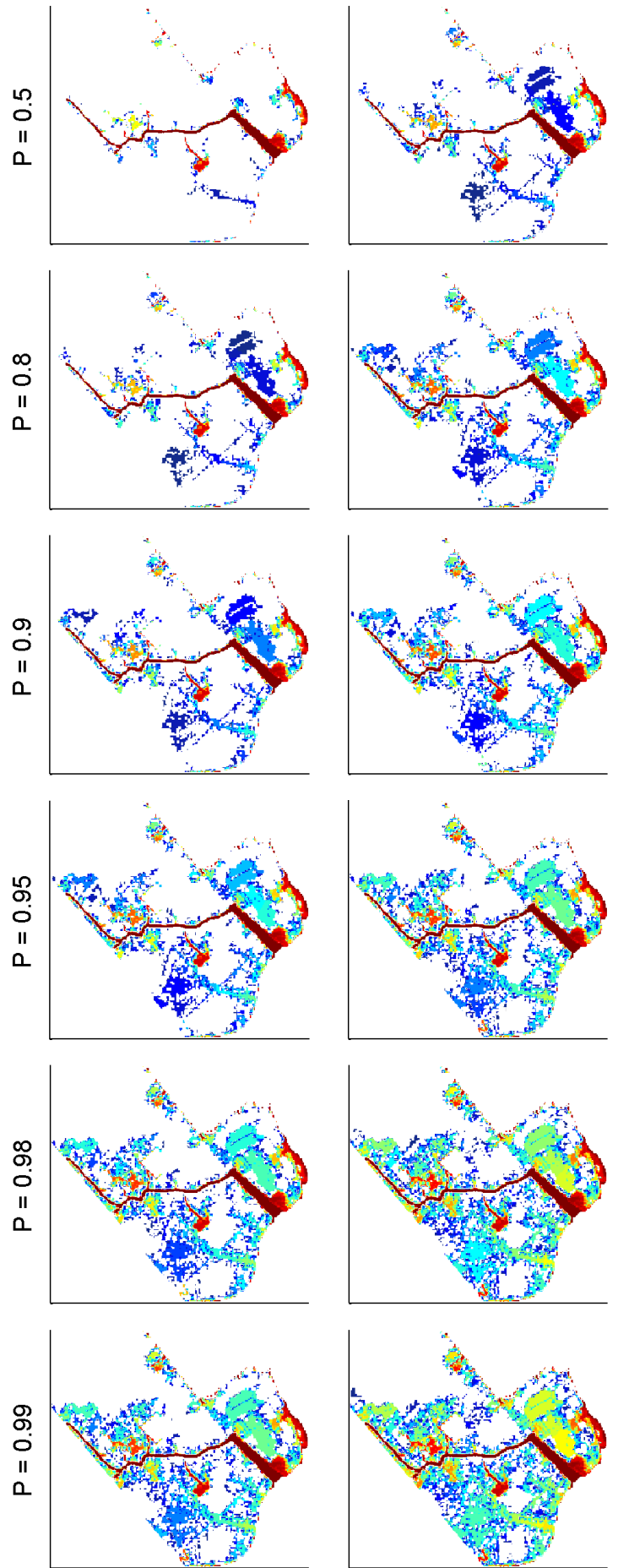

$95 \%$ quantile maps
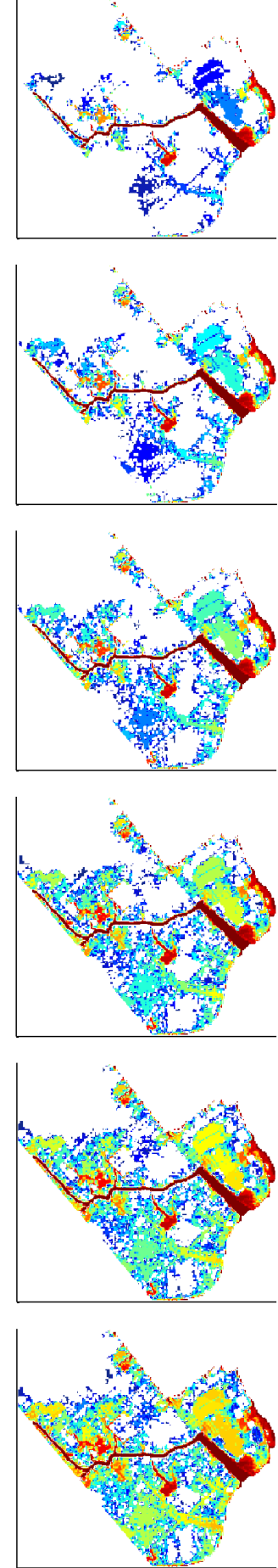

Inundation depth [m]

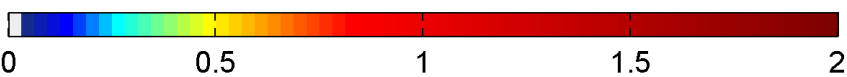

Figure 12. Probabilistic fluvial flood hazard maps for Can Tho showing maximum inundation depths: for the selected $p$ levels (annual probabilities of non-exceedance) the median (50\% quantile) maps and associated 5 and $95 \%$ quantile maps are shown illustrating the uncertainty of the hazard estimation. Maximum inundation depths $<0.02 \mathrm{~m}$ are indicated as no inundation. 
Table 2. Statistical evaluation of probabilistic hazard maps: mean maximum inundation depths and inundated area for every hazard map (annual probabilities of non-exceedance and percentile maps). For the statistics the channel and the river boundary cells were excluded, as well as cells with maximum inundation depths $<0.02 \mathrm{~m}$.

\begin{tabular}{|c|c|c|c|c|c|c|}
\hline \multirow[b]{2}{*}{$\begin{array}{l}\text { Annual } \\
\text { probability } \\
\text { of non- } \\
\text { exceedance }\end{array}$} & \multicolumn{2}{|c|}{$5 \%$ percentile maps } & \multicolumn{2}{|c|}{$50 \%$ percentile maps } & \multicolumn{2}{|c|}{$95 \%$ percentile maps } \\
\hline & $\begin{array}{c}\text { Mean } \\
\text { maximum } \\
\text { inundation } \\
\text { depth }[\mathrm{m}]\end{array}$ & $\begin{array}{c}\text { Inundated } \\
\text { area }\left[\mathrm{km}^{2}\right]\end{array}$ & $\begin{array}{c}\text { Mean } \\
\text { maximum } \\
\text { inundation } \\
\text { depth }[\mathrm{m}]\end{array}$ & $\begin{array}{c}\text { Inundated } \\
\text { area }\left[\mathrm{km}^{2}\right]\end{array}$ & $\begin{array}{c}\text { Mean } \\
\text { maximum } \\
\text { inundation } \\
\text { depth }[\mathrm{m}]\end{array}$ & $\begin{array}{l}\text { Inundated } \\
\text { area }\left[\mathrm{km}^{2}\right]\end{array}$ \\
\hline \multicolumn{7}{|c|}{ Fluvial hazard maps } \\
\hline 0.5 & 0.44 & 1.16 & 0.31 & 2.37 & 0.31 & 2.74 \\
\hline 0.8 & 0.31 & 2.27 & 0.31 & 3.33 & 0.32 & 3.73 \\
\hline 0.90 & 0.31 & 2.83 & 0.32 & 3.71 & 0.33 & 4.41 \\
\hline 0.95 & 0.31 & 3.45 & 0.33 & 4.30 & 0.35 & 5.10 \\
\hline 0.98 & 0.32 & 4.05 & 0.35 & 4.98 & 0.37 & 5.54 \\
\hline 0.99 & 0.33 & 4.34 & 0.36 & 5.29 & 0.40 & 5.97 \\
\hline \multicolumn{7}{|c|}{ Pluvial hazard maps } \\
\hline 0.5 & 0.11 & 0.25 & 0.06 & 3.32 & 0.09 & 5.43 \\
\hline 0.8 & 0.05 & 1.28 & 0.07 & 4.41 & 0.10 & 5.91 \\
\hline 0.90 & 0.05 & 3.07 & 0.08 & 5.12 & 0.11 & 6.23 \\
\hline 0.95 & 0.06 & 3.87 & 0.09 & 5.56 & 0.11 & 6.49 \\
\hline 0.98 & 0.08 & 4.62 & 0.11 & 6.18 & 0.12 & 6.77 \\
\hline 0.99 & 0.09 & 5.32 & 0.11 & 6.43 & 0.13 & 6.94 \\
\hline \multicolumn{7}{|c|}{ Fluvial-pluvial hazard maps } \\
\hline 0.95 & 0.27 & 2.04 & 0.20 & 4.28 & 0.18 & 5.98 \\
\hline 0.992 & 0.23 & 3.43 & 0.22 & 5.53 & 0.22 & 6.52 \\
\hline 0.998 & 0.21 & 4.65 & 0.22 & 6.11 & 0.24 & 6.86 \\
\hline 0.9995 & 0.23 & 5.25 & 0.24 & 6.48 & 0.28 & 7.11 \\
\hline 0.99992 & 0.24 & 6.04 & 0.27 & 6.97 & 0.31 & 7.32 \\
\hline 0.99998 & 0.25 & 6.43 & 0.29 & 7.14 & 0.35 & 7.46 \\
\hline
\end{tabular}

the uncertainty in the flood hazard in Can Tho city as shown in Fig. 12.

This uncertainty is also shown in Table 2 comparing the inundated areas between the quantile maps. These underline the visual impression of Fig. 12. The numbers indicate that the differences in inundation extent is higher between the 5 and $50 \%$ quantile maps compared to the 50 and $95 \%$ quantile maps. This effect is less visible in the numbers of the mean maximum inundation depths. The $5 \%$ quantile map of $p$ level 0.5 shows even higher mean maximum inundation depths than the higher quantile maps. This is a statistical effect caused by the relatively few inundated grid cells, which are along the main inundation hot spots, all of them showing comparatively high maximum inundation depths.

\subsection{Pluvial hazard}

The pluvial hazard maps are shown in the same format as the fluvial hazard maps in Fig. 13. On first glance the distinctively different characteristics of the pluvial hazard maps become obvious. The hazard maps neither show featured flow paths nor particular hot spots of inundation. This is caused by the nature of the boundary conditions providing spatially distributed input, in combination with the Monte Carlo selection of random storm centre locations. As a result the pluvial hazard maps look much more uniform compared to the fluvial hazard maps. The inundation patterns show the topographical depressions as given by the DEM rather than actual flow paths. It has to be mentioned that the proposed methodology of random storm locations and variable spatial extent and intensity of the synthetic rainstorms yields characteristically different hazard maps compared to the assumption of spatially uniform coverage of the whole simulation domain. Spatially uniform rainstorms would produce different quantile maps, which would look more uniform over the whole simulation domain. And even more importantly, the inundation depths would be deeper due to the higher rainfall volume given by a uniform coverage compared to the synthetic storm events derived in Sect. 3.2.2.

As shown in Table 2 and visible in Fig. 13, the mean maximum inundation depths of the pluvial maps are much lower for all $p$ levels compared to the fluvial hazard maps. For the 


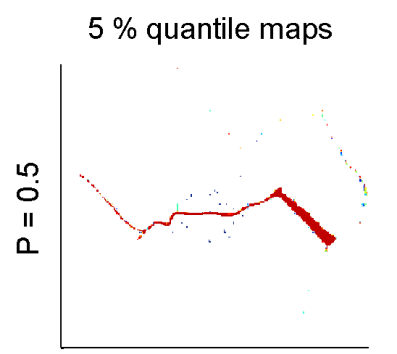

$50 \%$ quantile maps
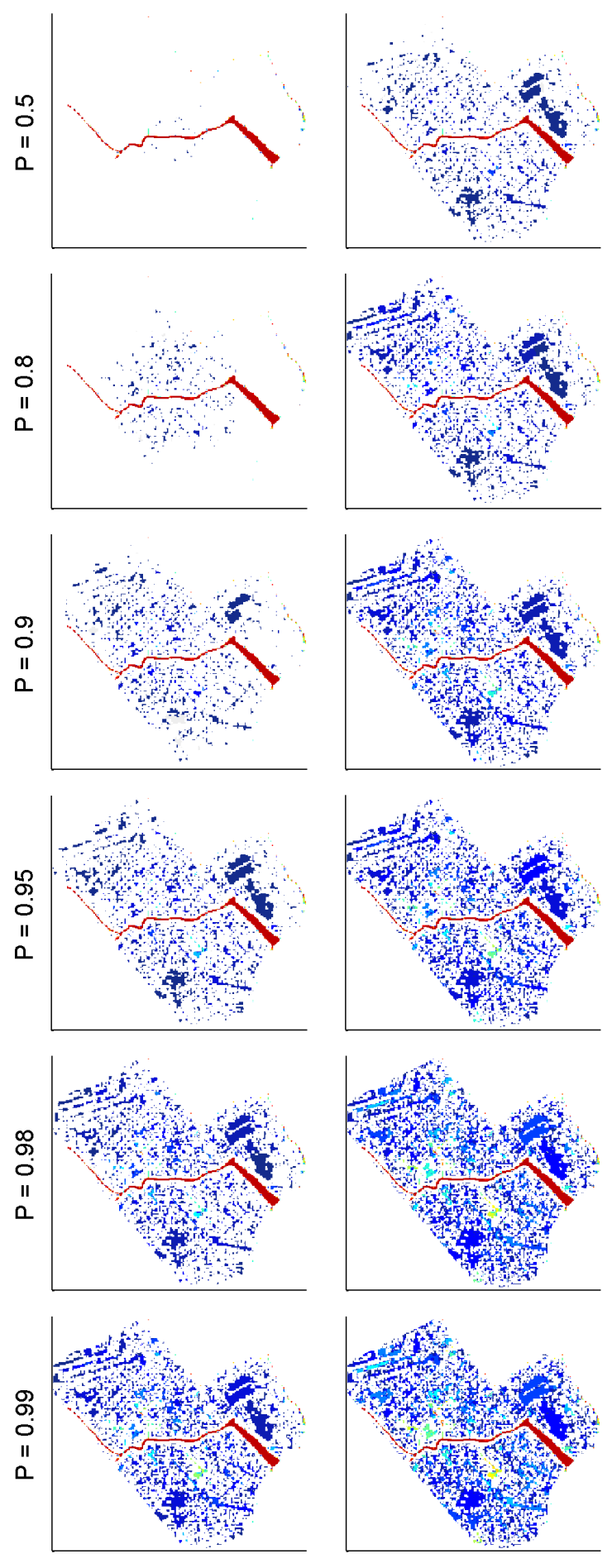

Inundation depth [m]
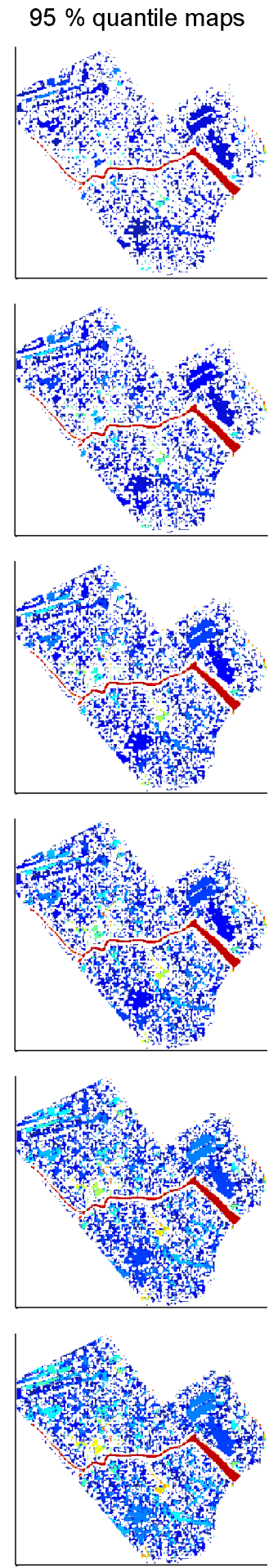

1.5

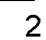

Figure 13. Probabilistic pluvial flood hazard maps for Can Tho showing maximum inundation depths: for the selected $p$ levels (annual probabilities of non-exceedance) the median (50\% quantile) maps and associated 5 and $95 \%$ quantile maps are shown illustrating the uncertainty of the hazard estimation. Maximum inundation depths $<0.02 \mathrm{~m}$ are indicated as no inundation. 
$50 \%$ quantile maps they range between 6 and $11 \mathrm{~cm}$. However, the inundation extent is higher compared to the fluvial maps due to the spatially distributed rainstorms. For the $50 \%$ quantile maps the inundation area is always roughly $1 \mathrm{~km}^{2}$ larger.

The uncertainty of the pluvial hazard maps as shown by the 5 and $95 \%$ quantile maps is of particular interest. This uncertainty is considerably larger compared to the fluvial hazard maps. As clearly visible in Fig. 13 and quantified in Table 2 the difference between the quantile maps in terms of inundation extent is much larger with the pluvial hazard maps, particularly for the lower $p$ levels. The uncertainty range given by the quantile maps is actually in the same range as between the median of the lowest and highest $p$ level. This holds true for both mean maximum inundation depths and inundation extent, as shown in Table 2. Solely the mean maximum inundation depth between the quantile maps for $p$ level 0.5 does not follow this rule, because of the same statistical effect in calculating the mean maximum inundation depth for the $5 \%$ quantile map. The wide uncertainty range becomes particularly obvious by comparing the $95 \%$ quantile map for $p$ level 0.5 and the $5 \%$ quantile map for $p$ level 0.99 , for both mean maximum inundation depths and inundation extent. These maps are almost identical.

This phenomenon is a direct consequence of the random nature of the location of the storm centres. In the absence of defined inundation pathways, this random distribution of the storm centres causes the different inundation patterns and thus the characteristics of the quantile maps. The $95 \%$ quantile map of the $p$ level 0.5 basically shows inundations caused by the centre of a small rainstorm hitting by chance a defined are of the simulation domain. On the contrary, the $5 \%$ quantile map of the $p$ level 0.99 show the inundation caused by the borders of a large storm that actually hit another part of the city. Due to the different storm magnitudes this results in similar quantile maps for different $p$ levels. Assuming that the assumptions for the derivation of the synthetic storm events (cf. Sect. 3.2.2) are reasonable, this is not only a consequence of the proposed method, but also of the very nature of the rainstorms causing inundation, and thus a characteristic feature of pluvial hazard maps under a pre-dominantly convective rainfall regime.

\subsection{Combined fluvial-pluvial hazard}

The joint fluvial-pluvial hazard maps (Fig. 14) combine the characteristics of the individual hazard maps. They show the same distinct inundation hot spots with deeper maximum inundation depths and flow pathways as the fluvial maps, complemented by the spatially more uniform but lower inundation depths of the pluvial hazard maps. In general the fluvial inundation is dominant, i.e. causes the deeper inundations, while the pluvial inundation plays a role only in places where no fluvial inundation occurs. These areas are mainly the yet unnamed industrial park in the An Hòa ward at the north- west corner of the simulation domain, and the Thôui Bình ward west of the $90^{\circ}$ bend of the domain boundary.

Interestingly, the maximum inundation depths in the fluvial-dominated areas differ only slightly (max. a few $\mathrm{mm}$ ) from the fluvial hazard maps. This indicates that the fluvial processes are not significantly altered by the additional pluvial input. This is caused by the smaller duration and thus smaller flood water volume of the rainstorms compared to the fluvial inundation.

The interplay of fluvial and pluvial inundation results in overall larger inundation extents compared to both fluvial and pluvial hazard maps alone (cf. Table 2). The mean maximum inundation depths, however, are lower compared to the fluvial maps, which is again a statistical effect accounting for the larger number of inundated cells with low inundation depths stemming from the pluvial input.

The percentile maps quantifying the natural uncertainty also show features of both fluvial and pluvial uncertainty maps. In the fluvial-dominated inundation areas, uncertainty within each probability level is smaller than the difference between the median of all probability levels. The uncertainty within the $p$ levels is skewed, i.e. the difference in inundation extent between the 5 and $50 \%$ percentile maps is larger than between the 50 and $95 \%$ percentile maps. However, for the pluvial-dominated inundation areas the same large uncertainty as for the pluvial hazard maps can be observed.

\section{Sensitivity of coincidence}

The core assumption of the combined hazard analysis is the exact coincidence of the rainstorm with the maximum water level in the Hau River. In order to rule out artefacts caused by this assumption, a parallel combined hazard analysis, in which the rainstorm can occur randomly in a time window of $\pm 3 \mathrm{~h}$ around the maximum water level was performed. A comparison of the final probabilistic hazard maps with the exact match maps showed only minor differences in maximum inundation depth and extent in the range of a few millimetres. Given the nature of the processes and the uncertainties in the DEM and input data this is negligible. This means that in the combined hazard analysis the specific point in time of coincidence of rainstorm and fluvial inundation is not of major importance, at least for the used criteria of maximum inundation depth and extent. It can be suspected that the timing of the rainstorm within the fluvial event plays a more pronounced role if fluvial and pluvial events of different probabilities of occurrence are combined, e.g. a fluvial event with $p=0.5$ combined with a pluvial event of $p=0.99$. However, as these combinations were not simulated this can only be speculated with the current results at hand.

Spatial coincidence of the flood triggers also proved to be of minor importance. The fact that the maximum inundation depths of the combined analysis do not differ much from the fluvial analysis could indicate that with the given set of 140 Monte Carlo combinations, the random storm centres do 

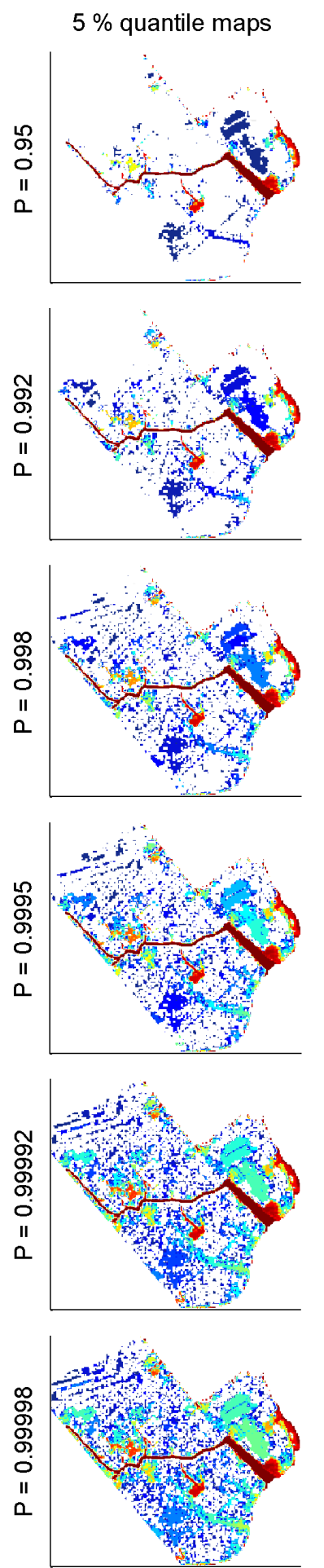

$50 \%$ quantile maps

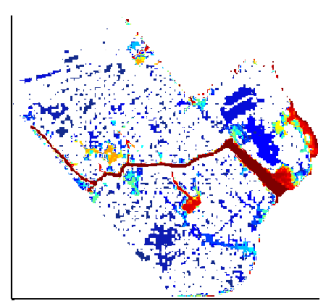

$95 \%$ quantile maps
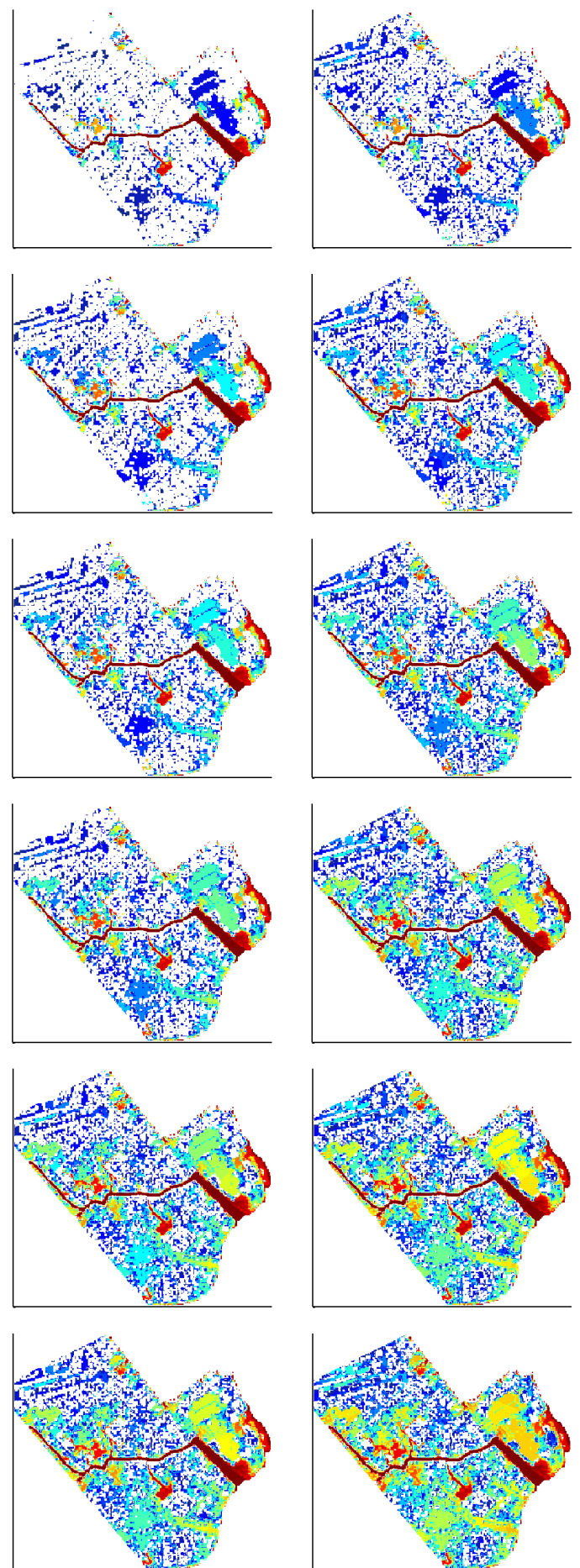

Inundation depth [m]
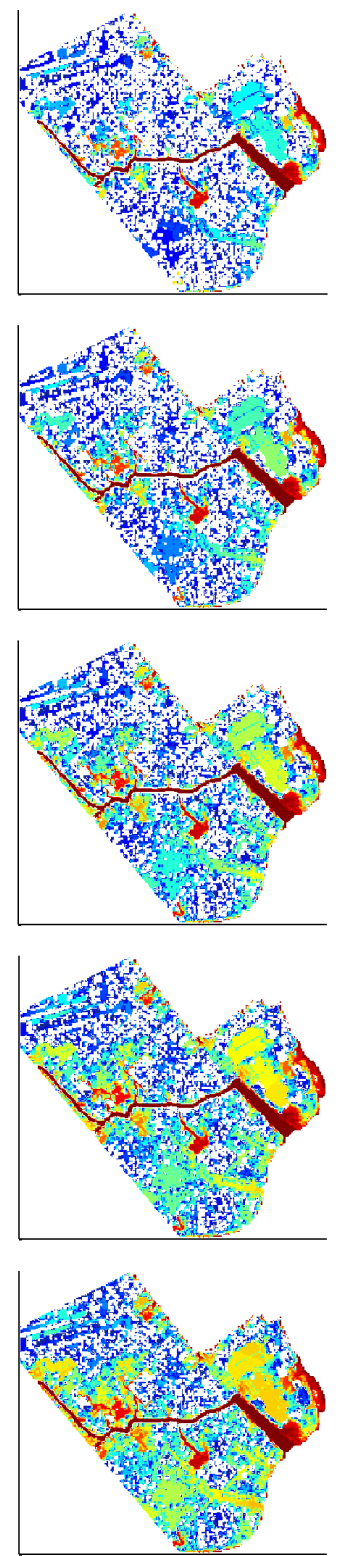

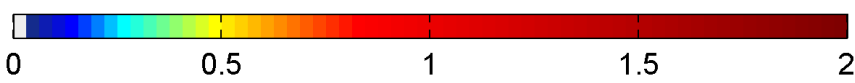

Figure 14. Probabilistic combined fluvial-pluvial flood hazard maps for Can Tho showing maximum inundation depths: for the derived $p$ levels (annual probabilities of non-exceedance), the median (50\% quantile) maps and associated 5 and $95 \%$ quantile maps are shown illustrating the uncertainty of the hazard estimation. Note that the $p$ levels are different to the fluvial and pluvial hazard maps due to the discrete combinations of fluvial and pluvial $p$ levels. Maximum inundation depths $<0.02 \mathrm{~m}$ are indicated as no inundation. 
not fall in the areas where the fluvial inundation is highest. An increase of the Monte Carlo runs could clarify this question. However, although the simulation time with the models and hardware at hand are in acceptable limits, simulation time is still a prohibitive factor in this respect.

\subsection{Implications for risk assessment}

Combining fluvial and pluvial flood events in a hazard analysis has implications for estimating flood risk. In flood risk assessments (FRAs), the occurrence of fluvial, pluvial and combined flood events and their probabilities have to be taken into account. While a combination of fluvial and pluvial hazard without any interaction can be considered straightforwardly as the sum of the individual hazards and associated risks, the inclusion of the combined hazard requires the consideration that parts of the fluvial and pluvial scenarios coincide. In the following the formal consideration of this coincidence in a risk assessment is derived for the calculation of expected annual damages (EADs). EADs are defined as the product of the annual probability of exceedance of a given flood event and the damage it inflicts. For a discrete set of scenarios, i.e. probability levels as used in this study, EADs are formulated as the following:

$\mathrm{EAD}=\sum_{i=1}^{n} \Delta P_{i} \cdot D_{i}$

where $\Delta P$ is the increment of annual probability of exceedance $=\Delta(1-p)$, with $p$ as the annual probability of non-exceedance; $D$ is the damage inflicted; $i$ is the numerator of the probability levels considered, and $n$ is the number of probability levels. As this formulation is an approximation of the integration of a (hypothetical) continuous risk curve, the annual probability of exceedance and the damage have to be interpolated between the $p$ levels (Ward et al., 2011; Merz et al., 2009). Using a linear interpolation $\Delta P_{i}$ and $D_{i}$ are defined as the following:

$D_{i}=\frac{1}{2}\left(D_{i+1}+D_{i}\right)$

$\Delta P_{i}=P_{i+1}-P_{i}$.

If the fluvial (fl) and pluvial (pl) hazards were not coinciding, the EADs for combined fluvial and pluvial risk would be simply the sum of $\operatorname{EAD}(\mathrm{fl})$ and $\operatorname{EAD}(\mathrm{pl})$. However, in the presented study the fluvial and the pluvial hazard can coincide, and this has to be taken into account in the calculation of the overall EAD. Formally this is achieved by reducing the annual probability of exceedance of the individual hazards by the annual probability of exceedance of the combined hazard:

$$
\begin{aligned}
\operatorname{EAD}(\mathrm{fl}, \mathrm{pl}, \mathrm{fl} \cdot \mathrm{pl}) & =\sum_{i=1}^{n} \Delta\left[P(\mathrm{fl})_{i}-P(\mathrm{fl} \cdot \mathrm{pl})_{i}\right] \cdot D(\mathrm{fl})_{i} \\
& +\sum_{i=1}^{n} \Delta\left[P(\mathrm{pl})_{i}-P(\mathrm{fl} \cdot \mathrm{pl})_{i}\right] \cdot D(\mathrm{pl})_{i} \\
& +\sum_{i=1}^{n} \Delta P(\mathrm{fl} \cdot \mathrm{pl})_{i} \cdot D(\mathrm{fl} \cdot \mathrm{pl})_{i} .
\end{aligned}
$$

This formulation is valid for the presented combination of fluvial and pluvial probability levels, which are identical in each combination. If a complete permutation of the probability levels is performed, the additional scenarios and their probabilities must also be considered analogously as in the special case presented here. Formally this is expressed as an extension of the formula above:

$$
\begin{aligned}
\operatorname{EAD}(\mathrm{fl}, \mathrm{pl}, \mathrm{fl} \cdot \mathrm{pl}) & =\sum_{i=1}^{n} \Delta\left[P(\mathrm{fl})_{i}-\sum_{j=1}^{n} P(\mathrm{fl} \cdot \mathrm{pl})_{i, j}\right] \cdot D(\mathrm{fl})_{i} \\
& +\sum_{i=1}^{n} \Delta\left[P(\mathrm{pl})_{i}-\sum_{j=1}^{n} P(\mathrm{fl} \cdot \mathrm{pl})_{i}\right] \cdot D(\mathrm{pl})_{i} \\
& +\sum_{i=1}^{n} \sum_{j=1}^{n} \Delta P(\mathrm{fl} \cdot \mathrm{pl})_{i, j} \cdot D(\mathrm{fl} \cdot \mathrm{pl})_{i, j} \cdot
\end{aligned}
$$

\subsection{Limitations of the approach}

Although the presented results appear to be plausible and are accompanied by uncertainty estimations, it is clear that such comprehensive approaches have their limitations. This section identifies and discusses the most important limitations.

The developed methodology considers the natural (aleatory) uncertainty only, i.e. the uncertainty stemming from the natural variability of the flood triggering events. In the fluvial analysis the variability of the occurrences of flood peak and flood volume, and the hydrograph shape at the upper boundary of the Mekong Delta were taken into account in this respect. In the pluvial analysis natural variability was mapped by the magnitude and location of rainstorm events. However, the quantification of these uncertainties is also plagued with uncertainty, which is termed epistemic uncertainty. This generally stems from imperfect knowledge of the processes, insufficient data or models. For example, for the fluvial analysis Dung et al. (2015) showed that the bivariate frequency analysis is associated with considerable epistemic uncertainty stemming from a limited length of the data series. This uncertainty is not considered in the presented study. Technically, a consideration of this uncertainty source would mean an extension of the Monte Carlo analysis, in which even more pairs of flood peak $Q_{\max }$ and flood volume $V$ per probability level have to be considered. Whether this is feasible, is mainly a question of simulation time. The resulting percentile maps would certainly show a wider range compared to this study. The same holds true if other epistemic uncertainty sources were considered. 
The pluvial analysis also contains epistemic uncertainty which was also not quantified. The epistemic uncertainty is associated to the assumptions listed in Sect. 3.2.2. The assumptions on storm extent and spatial distribution of intensity have particularly large impacts on the inundation simulation and thus the probabilistic hazard maps. Unfortunately, no data for the validation of the assumptions were available to the authors, and thus a quantification of the uncertainty caused by the assumptions cannot be performed. An evaluation of radar rain data of the area, as e.g. performed in Barnolas et al. (2010), would be of great benefit for the characterisation and thus the validation of the assumptions taken.

The analysis of the spatial distribution of maximum rainfall intensities within the Monte Carlo analysis revealed a small negative bias (cf. Sect. 3.2.2). While this bias is already small, a increase of the random storm centre location, i.e. a higher number of Monte Carlo runs, would diminish this bias. In a test the bias was reduced to virtually zero in a MC run with 1000 random storm centres. This would of course increase the computational time considerably, particularly for the combined fluvial-pluvial events. The question of what is an acceptable bias is thus a compromise between desired accuracy and practical considerations. Although the test for the bias introduced by the assumption of the synthetic rainstorms is not encompassing, it can be stated for the presented test case that if a bias of less than $1 \%$ is regarded acceptable, the quotient derived by the division of the area of the simulation domain $\left[\mathrm{m}^{2}\right]$ by the product of Monte Carlo runs and FWTM [m] of the synthetic storms should be smaller than 16. This may be used as a rough guideline for similar studies.

Further sources of epistemic uncertainty are the hydraulic model and the quality of the DEM. While the horizontal resolution is acceptable for a study of this scale, the quality of the vertical information has to be critically assessed. Because the DEM was interpolated from elevation information of topographical maps, it has to be expected that the accuracy is actually not sufficient for urban inundation simulation. Additional uncertainty is caused by the lack of calibration and validation of the hydraulic model due to insufficient data. However, sensitivity runs with different distributions and values of roughness parameters indicate that the uncertainty in maximum inundation depths is dominated by the topography and not by the parameterization of roughness values.

These uncertainties have to be taken into account when using the derived hazard maps for actual flood management planning. It is recommended to use the maps mainly for the identification of the most affected areas, and to use the inundation depths with caution.

\section{Conclusions}

This study develops a methodology for a combined fluvial and pluvial flood hazard analysis. The methodology is exemplarily developed for Can Tho city, which is the economic centre of the Vietnamese part of the Mekong Delta. Both fluvial and pluvial inundation processes cause regular flooding in Can Tho city. Both fluvial and pluvial hazard analyses contain a dedicated statistical part to estimate the probabilities of occurrence of floods of different magnitudes. Synthetic flood events were derived based on this frequency analysis, which provide the boundary conditions for a 2-dimensional inundation modelling of the central part of the city. With the help of the hydraulic model, maximum inundation depths were determined for every flood scenario for Can Tho city.

The two flood hazards were not only considered independent from each other, but also in combination, i.e. occurring at the same time. Because fluvial and pluvial flooding occurs in the same period of the year, these events can coincide. As the triggering events are essentially independent from each other, the probability of occurrence of coinciding events can be directly calculated from the probability of occurrences of the individual events and the probability of coincidence of the events. The resulting inundation events bear features of both fluvial and pluvial inundation processes. The presented method is novel not only in terms of the specific application for Can Tho city, but also in general, as a similar study has not been published so far. The presented methods can be transferred to other cities in a similar tropical setting and adapted to different climate zones.

The hazard analyses also include uncertainty estimations. For the fluvial, pluvial, and combined hazard the natural uncertainty, i.e. variability of flood events with identical probabilities of occurrence, was taken into account. This facilitated the derivation of probabilistic hazard maps showing the maximum inundation depths with an expectation, i.e. the median hazard map, and percentile maps quantifying the natural uncertainty in a spatially explicit manner. These maps can serve as a basis for flood management and mitigation plans, for a flood risk assessment for Can Tho city, or for cost-benefit analyses of flood protection measures. The derived hazard maps are available as GeoTiffs ready for use in a GIS in the Supplement related to this paper.

However, for usage of the hazard maps in practical applications the limitations, resp. the epistemic uncertainty which was not quantified - have to be taken into account. In this respect the quality of the digital elevation model and the assumptions underlying the derivation of synthetic rainstorm events have the highest impact on the final hazard estimates, particularly the maximum inundation depths. Thus for the time being, the maps should be mainly used for the determination of the most affected areas, and the maximum inundation depths should be taken as rough guidance only. Considering the prominent damage pathways - inundation of houses by water levels in the streets exceeding road curbs - a possi- 
ble way of direct usage of the maps could be to target flood mitigation plans to areas with maximum inundation depths exceeding a certain threshold, e.g. $10 \mathrm{~cm}$. This would eliminate the random character of the pluvial maps and thus the influence of the assumptions taken on rainstorm extent and storm centre locations. In order to increase the overall confidence in the hazard maps, the assumptions on rains storms should be validated, preferably by an analysis of a series of rain radar maps. Additionally, an improved DEM should be obtained and the hydraulic simulations repeated.

In any case, the presence of two or more hazard sources and their combination have to be taken into account in any risk assessment in a statistically sound and consistent manner. In general, the probability of occurrence of combined flood events reduces the probabilities of occurrence of individual fluvial and pluvial events of the same magnitude, which needs to be reflected in the risk calculations. How this can be achieved, has been exemplarily shown for a hypothetical calculation of expected annual damages (EADs), a standard risk variable.

Given the fact that the hydrometeorological setting of Can Tho city is similar to many low-lying cities in the tropics, the presented methodology can be used as a blueprint for flood hazard analysis in these cities. Due to the convective nature of tropical rainfall, the developed method for a probabilistic pluvial flood hazard analysis should be easily transferable. The fluvial part, however, should be modified to match the hydrological situation at hand. In most cases this means a simplification compared to the presented study, because such complicated hydraulic situations as in the Mekong Delta are not very frequent.

However, if the independence of the fluvial and pluvial flood events is not given, the approach has to be modified in order to take the dependence structure into account. This may be achieved by analysis of sufficient long time series of river discharge/water level and precipitation or by an approach similar to Breinl et al. (2015), utilizing a large-scale weather generator and a hydrological model.

\section{The Supplement related to this article is available online at doi:10.5194/nhess-16-941-2016-supplement.}

Acknowledgements. This study was conducted within the framework of the WISDOM project which was funded by the German Ministry of Education and Research BMBF (FKZ 033L040DN) and the Vietnamese Ministry of Science and Technology MOST. Funding by the ministries and support from various Vietnamese administrative bodies is gratefully acknowledged.

The article processing charges for this open-access

publication were covered by a Research

Centre of the Helmholtz Association.

Edited by: M.-C. Llasat

Reviewed by: two anonymous referees

\section{References}

Apel, H., Thieken, A. H., Merz, B., and Blöschl, G.: Flood risk assessment and associated uncertainty, Nat. Hazards Earth Syst. Sci., 4, 295-308, doi:10.5194/nhess-4-295-2004, 2004.

Apel, H., Merz, B., and Thieken, A. H.: Quantification of uncertainties in flood risk assessments, Int. J. River Basin Manage., 6, 149-162, 2008.

Apel, H., Aronica, G., Kreibich, H., and Thieken, A.: Flood risk analyses - how detailed do we need to be?, Nat. Hazards, 49, 79-98, 2009.

Arrighi, C., Brugioni, M., Castelli, F., Franceschini, S., and Mazzanti, B.: Urban micro-scale flood risk estimation with parsimonious hydraulic modelling and census data, Nat. Hazards Earth Syst. Sci., 13, 1375-1391, doi:10.5194/nhess-13-13752013, 2013.

Barnolas, M., Rigo, T., and Llasat, M. C.: Characteristics of 2-D convective structures in Catalonia (NE Spain): an analysis using radar data and GIS, Hydrol. Earth Syst. Sci., 14, 129-139, doi:10.5194/hess-14-129-2010, 2010.

Bates, P. D., Horritt, M. S., and Fewtrell, T. J.: A simple inertial formulation of the shallow water equations for efficient twodimensional flood inundation modelling, J. Hydrol., 387, 33-45, doi:10.1016/j.jhydrol.2010.03.027, 2010.

Blanc, J., Hall, J. W., Roche, N., Dawson, R. J., Cesses, Y., Burton, A., and Kilsby, C. G.: Enhanced efficiency of pluvial flood risk estimation in urban areas using spatial-temporal rainfall simulations, J. Flood Risk Manage., 5, 143-152, doi:10.1111/j.1753318X.2012.01135.x, 2012.

Breinl, K., Strasser, U., Bates, P., and Kienberger, S.: A joint modelling framework for daily extremes of river discharge and precipitation in urban areas, J. Flood Risk Manage., doi:10.1111/jfr3.12150, in press, 2015.

Burton, A., Kilsby, C. G., Fowler, H. J., Cowpertwait, P. S. P., and O'Connell, P. E.: RainSim: A spatial-temporal stochastic rainfall modelling system, Environ. Model. Softw., 23, 1356-1369, doi:10.1016/j.envsoft.2008.04.003, 2008.

Chan, F. K. S., Mitchell, G., Adekola, O., and McDonald, A.: Flood Risk in Asia's Urban Mega-deltas: Drivers, Impacts and Response, Environ. Urbaniz. Asia, 3, 41-61, doi:10.1177/097542531200300103, 2012.

Chen, A. S., Djordjevic, S., Leandro, J., and Savic, D. A.: An analysis of the combined consequences of pluvial and fluvial flooding, Water Sci. Technol., 62, 1491-1498, 2010.

Chinh, D. T., Bubeck, P., Dung, N. V., and Kreibich, H.: The 2011 flood event in the Mekong Delta: preparedness, response, damage and recovery of private households and small businesses, Disasters, doi:10.1111/disa.12171, in press, 2016.

de Almeida, G. A. M. and Bates, P.: Applicability of the local inertial approximation of the shallow water equations to flood modelling, Water Resour. Res., 49, 4833-4844, doi:10.1002/wrcr.20366, 2013.

de Bruijn, K. M., Diermanse, F. L. M., and Beckers, J. V. L.: An advanced method for flood risk analysis in river deltas, applied to societal flood fatality risk in the Netherlands, Nat. Hazards Earth Syst. Sci., 14, 2767-2781, doi:10.5194/nhess-14-27672014, 2014.

Dimitriadis, P., Tegos, A., Oikonomou, A., Pagana, V., Koukouvinos, A., Mamassis, N., Koutsoyiannis, D., and Efstratiadis, A.: Comparative evaluation of $1 \mathrm{D}$ and quasi-2D hydraulic mod- 
els based on benchmark and real-world applications for uncertainty assessment in flood mapping, J. Hydrol., 534, 478-492, doi:10.1016/j.jhydrol.2016.01.020, 2016.

Dung, N. V., Merz, B., Bárdossy, A., Thang, T. D., and Apel, H.: Multi-objective automatic calibration of hydrodynamic models utilizing inundation maps and gauge data, Hydrol. Earth Syst. Sci., 15, 1339-1354, doi:10.5194/hess-15-1339-2011, 2011.

Dung, N. V., Merz, B., Bárdossy, A., and Apel, H.: Handling uncertainty in bivariate quantile estimation - An application to flood hazard analysis in the Mekong Delta, J. Hydrol., 527, 704-717, doi:10.1016/j.jhydrol.2015.05.033, 2015.

Falter, D., Schröter, K., Dung, N. V., Vorogushyn, S., Kreibich, H., Hundecha, Y., Apel, H., and Merz, B.: Spatially coherent flood risk assessment based on long-term continuous simulation with a coupled model chain, J. Hydrol., 524, 182-193, doi:10.1016/j.jhydrol.2015.02.021, 2015.

Fewtrell, T. J., Duncan, A., Sampson, C. C., Neal, J. C., and Bates, P. D.: Benchmarking urban flood models of varying complexity and scale using high resolution terrestrial LiDAR data, Phys. Chem. Earth, 36, 281-291, doi:10.1016/j.pce.2010.12.011, 2011.

Hall, J. W., Sayers, P. B., and Dawson, R. J.: National-scale Assessment of Current and Future Flood Risk in England and Wales, Nat. Hazards, 36, 147-164, 2005.

Hundecha, Y., Pahlow, M., and Schumann, A.: Modeling of daily precipitation at multiple locations using a mixture of distributions to characterize the extremes, Water Resour. Res., 45, W12412, doi:10.1029/2008wr007453, 2009.

Huong, H. T. L. and Pathirana, A.: Urbanization and climate change impacts on future urban flooding in Can Tho city, Vietnam, Hydrol. Earth Syst. Sci., 17, 379-394, doi:10.5194/hess-17-3792013, 2013.

Huth, J., Kuenzer, C., Wehrmann, T., Gebhardt, S., Tuan, V. Q., and Dech, S.: Land Cover and Land Use Classification with TWOPAC: towards Automated Processing for Pixel- and ObjectBased Image Classification, Remote Sensing, 4, 2530-2553, 2012.

Kuenzer, C., Campbell, I., Roch, M., Leinenkugel, P., Tuan, V., and Dech, S.: Understanding the impact of hydropower developments in the context of upstream-downstream relations in the Mekong river basin, Sustain. Sci., 8, 565-584, doi:10.1007/s11625-0120195-z, 2013a.

Kuenzer, C., Guo, H., Schlegel, I., Tuan, V. Q., Li, X., and Dech, S.: Varying Scale and Capability of Envisat ASAR-WSM, TerraSAR-X Scansar and TerraSAR-X Stripmap Data to Assess Urban Flood Situations: A Case Study of the Mekong Delta in Can Tho Province, Remote Sensing, 5, 5122-5142, $2013 \mathrm{~b}$.

Manh, N. V., Dung, N. V., Hung, N. N., Merz, B., and Apel, H.: Large-scale suspended sediment transport and sediment deposition in the Mekong Delta, Hydrol. Earth Syst. Sci., 18, 30333053, doi:10.5194/hess-18-3033-2014, 2014.

McMillan, H. K. and Brasington, J.: End-to-end flood risk assessment: A coupled model cascade with uncertainty estimation, Water Resour. Res., 44, W03419, doi:10.1029/2007wr005995, 2008.
Merz, B. and Thieken, A. H.: Separating natural and epistemic uncertainty in flood frequency analysis, J. Hydrol., 309, 114-132, doi:10.1016/j.jhydrol.2004.11.015, 2005.

Merz, B., Elmer, F., and Thieken, A. H.: Significance of "high probability/low damage" versus "low probability/high damage" flood events, Nat. Hazards Earth Syst. Sci., 9, 1033-1046, doi:10.5194/nhess-9-1033-2009, 2009.

Merz, B., Hall, J., Disse, M., and Schumann, A.: Fluvial flood risk management in a changing world, Nat. Hazards Earth Syst. Sci., 10, 509-527, doi:10.5194/nhess-10-509-2010, 2010.

MunichRe: Natural Disasters 2014: https://www.munichre.com/ touch/naturalhazards/en/natcatservice/annual-statistics/index. html, last access: 25 February 2015.

Nuswantoro, R., Diermanse, F., and Molkenthin, F.: Probabilistic flood hazard maps for Jakarta derived from a stochastic rainstorm generator, J. Flood Risk Manage., doi:10.1111/jfr3.12114, in press, 2014.

Renaud, F. G., Syvitski, J. P. M., Sebesvari, Z., Werners, S. E., Kremer, H., Kuenzer, C., Ramesh, R., Jeuken, A., and Friedrich, J.: Tipping from the Holocene to the Anthropocene: How threatened are major world deltas?, Curr. Opin. Environ. Sustain., 5, 644-654, doi:10.1016/j.cosust.2013.11.007, 2013.

Syvitski, J. P. M.: Deltas at risk, Sustain. Sci., 3, 23-32, doi:10.1007/s11625-008-0043-3, 2008.

Syvitski, J. P. M. and Higgins, S.: Going under: The world's sinking deltas, New Scientist, 216, 40-43, doi:10.1016/S02624079(12)63083-8, 2012.

Takagi, H., Ty, T. V., Thao, N. D., and Esteban, M.: Ocean tides and the influence of sea-level rise on floods in urban areas of the Mekong Delta, J. Flood Risk Manage., 8, 292-300, doi:10.1111/jfr3.12094, 2015.

Thompson, C. M. and Frazier, T. G.: Deterministic and probabilistic flood modeling for contemporary and future coastal and inland precipitation inundation, Appl. Geogr., 50, 1-14, doi:10.1016/j.apgeog.2014.01.013, 2014.

Vorogushyn, S., Merz, B., Lindenschmidt, K. E., and Apel, H.: A new methodology for flood hazard assessment considering dike breaches, Water Resour. Res., 46, W08541, doi:10.1029/2009WR008475, 2010.

Ward, P. J., de Moel, H., and Aerts, J. C. J. H.: How are flood risk estimates affected by the choice of return-periods?, Nat. Hazards Earth Syst. Sci., 11, 3181-3195, doi:10.5194/nhess-113181-2011, 2011.

Wassmann, R., Hien, N. X., Hoanh, C. T., and Tuong, T. P.: Sea Level Rise Affecting the Vietnamese Mekong Delta: Water Elevation in the Flood Season and Implications for Rice Production, Climatic Change, 66, 89-107, doi:10.1023/B:CLIM.0000043144.69736.b7, 2004.

Wheater, H., Chandler, R., Onof, C., Isham, V., Bellone, E., Yang, C., Lekkas, D., Lourmas, G., and Segond, M.-L.: Spatialtemporal rainfall modelling for flood risk estimation, Stoch. Environ. Res. Risk A., 19, 403-416, 2005.

Willems, P.: A spatial rainfall generator for small spatial scales, J. Hydrol., 252, 126-144, doi:10.1016/S0022-1694(01)00446-2, 2001. 